Article

\title{
Toward Supply Chain Sustainability: Governance and Implementation of Joint Sustainability Development
}

\author{
Yongmei Xu ${ }^{1}$, Jiho Yoon ${ }^{2}$, Myung Kyo Kim ${ }^{2, *(1)}$ and Chwen Sheu ${ }^{2}$ \\ 1 Management School, Jinan University, Guangzhou 510632, China; txuym@jnu.edu.cn \\ 2 Department of Management, College of Business Administration, Kansas State University, \\ Manhattan, KS 66506, USA; jihoyoon@ksu.edu (J.Y.); csheu@ksu.edu (C.S.) \\ * Correspondence: myungkyo@ksu.edu; Tel.: +1-785-532-5762
}

Received: 19 April 2018; Accepted: 18 May 2018; Published: 21 May 2018

check for updates

\begin{abstract}
The extant sustainability literature has argued that supply chain (SC) members can gain both financial and operational benefits from a joint sustainability development (JSD) effort. However, no guidance has been provided on how SC members could collaborate on their sustainability development efforts to achieve the intended economic performance. This study addressed this research gap by proposing different contractual governances, based on a game-theoretic approach, for both manufacturer and retailer to better engage in JSD. Specifically, multiple JSD contractual arrangements regarding profit and associated cost sharing between manufacturers and retailers were defined and evaluated. Our analyses show that the manufacturer behaves opportunistically when the impact of a retailer's effort on consumer demand is low. In other words, the retailer increases its sustainability effort, but not the manufacturer. However, such opportunistic behavior can be removed under a revenue sharing arrangement. That is, the manufacturer becomes cooperative with the retailer, and both retailer and manufacturer increase their JSD efforts. Several numerical experiments were conducted to assess the effectiveness of various revenue sharing arrangements (no sharing, partial profit sharing, and total profit sharing) in devising and implementing a mutually beneficial JSD program. Accordingly, several guidelines for the SC JSD implementation are provided.
\end{abstract}

Keywords: sustainability development; sustainable supply chain; joint decision making; manufacturer-retailer relationship

\section{Introduction}

Corporate sustainability has received continuous attention from consumers and other stakeholders (e.g., supply chain partners, government, NGOs, local communities, etc.), and all businesses face market pressure to develop and manage sustainable practices across their value chains (e.g., [1,2]). Consumers are concerned, not only about the products themselves, but also the processes related to the products, including the labor conditions under which the products were produced and handled, and the environmental and societal impacts of processing raw material, work-in-progress, finished product stock, residual/recyclable wastes, etc. along the supply chain (SC) [3,4]. For instance, according to a recent survey by Cone Communications/Ebiquity Global CSR (2015), 90\% of consumers said they would boycott a company if they learned of irresponsible or deceptive business practices. In response, companies have spent a great deal of time and resources to develop sustainability, reduce their environmental footprints, and adopt socially responsible SC practices. For example, Nike, an American multinational sporting goods manufacturer, has invested heavily (\$25 million annually) [5] in providing better working conditions and more environmentally friendly products since its child labor scandal in 1996. In addition to their preference on "greener" products, consumers are also becoming more aware and critical of retailers' and manufacturers' roles and responsibilities in sustainability initiatives [6]. 
For example, the Campaign for Labor Rights' recent campaign against Nike called for a boycott of the sport retailer Footlocker because Footlocker is Nike's largest retail outlet and Nike is Footlocker's largest supplier, which is known as a secondary boycott. In response to this consumer demand, Walmart launched and refined The Sustainability Consortium initiative in 2009 and has made enormous efforts to reduce its energy and water consumption and waste emissions.

However, the current sustainability initiatives implemented by individual companies have not always translated into a company's sustainability performance. The International Labor Rights Forum accused Nike of blocking labor rights experts from assessing its supplier factories in 2017 [7]. Nike was also given a pathetic score of 36 out of 100 in Fashion Revolution's 2017 Fashion Transparency Index [8]. In 2015, Walmart was criticized for failing to set science-based targets for climate emissions or to speed up progress on renewables [9]. There are two perspectives offered to explain such disappointing outcomes. First, some researchers have conceptually argued that sustainability initiatives entail close collaboration between relevant SC members, rather than being entirely achieved by one focal company's leadership $[10,11]$. This perspective recognizes sustainability as a SC matter and underlines the collaboration between SC members as a key factor for successful implementation of a sustainability initiative $[12,13]$. The second perspective suggests the "fit" between SC position and sustainability initiative as another possible explanation. Narasimhan et al. [14], for example, found that the companies farther downstream in the SC (closer to final consumers) achieve greater financial benefits from Forest Stewardship Council (FSC) certification, a widely acknowledged international standard in the management and supply of sustainably produced timber. This finding alludes to the idea that upstream and downstream companies have different performance impacts of their sustainability efforts depending on their SC positions, which highlights the necessity of SC members' coordinated efforts on sustainability initiative.

Although those studies have drawn unprecedented interest in supply chain joint sustainability development (JSD), the extant research has remained largely conceptual or anecdotal due to the challenge of considering the opportunistic behaviors from supply chain partners. Namely, any company involved in JSD could behave opportunistically and not be motivated to make meaningful JSD efforts without collaborative agreement or contractual governance with its JSD counterpart $[15,16]$. This paucity of research is also reflected in practice [17]. A global survey by MIT Sloan Management Review and Boston Consulting Group [18], for instance, found that only $60 \%$ of responding companies have a coherent sustainability strategy that aligns their value and interests with those of other stakeholders.

Building on the aforementioned perspectives, this study aimed to close this theoretical and managerial gap by proposing different contractual governance arrangements for engaging SC partners in JSD in the context of a manufacturer-retailer relationship. The relationship between manufacturer and retailer has traditionally been viewed as adversarial in the literature [19], but both parties have incentives to work together in developing and implementing sustainability initiatives outside their own firms' boundaries. These days, retailers, to prevent secondary boycotts relating to manufacturers' sustainability failures, often dictate to manufacturers their own environmental requirements for product content and packaging rather than passively accepting what manufacturers and distributors offer [20]. Likewise, a retailer's JSD commitment is critical for a manufacturer in achieving its sustainability goals because of its proximity to final consumers and awareness of consumer demand, which are pivotal to developing and enforcing a sustainable SC [21]. The mutual dependence of Nike and Footlocker, in public perceptions of sustainability, well demonstrates these incentives and the necessity of pursuing JSD. Under mutually beneficial arrangements, therefore, both manufacturer and retailer will better translate their sustainability initiatives into corporate performance, such as positive brand/product images, loyal consumers, and increased consumer demand than manufacturer's or retailer's individual efforts [22].

This study applied a game theoretic approach to constitute solid evidence of the benefit of JSD (i.e., increased consumer demand), and further recommends useful contractual cost profit sharing arrangements (i.e., partial or full sharing) and decision-making sequence (i.e., manufacturer sets its 
wholesale price and sustainability development effort first and retailer follows) that minimize or remove opportunism and maximize gains in JSD. Specifically, the following three primary research questions were explored:

1. How does the impact of manufacturers' and retailers' individual sustainability development efforts on consumer demand influence their decisions in terms of pricing (i.e., wholesale and retail prices) and their JSD effort levels?

2. How do the revenue sharing arrangements (i.e., partial sharing (unit profit margin sharing without associated fixed costs sharing) and full sharing (unit profit margin and associated fixed costs sharing)) affect manufacturers' and retailers' decisions on initiating their JSD?

3. Is it possible to identify a particular contractual arrangement (i.e., derivative of revenue sharing) that is preferred by both manufacturer and retailer simultaneously?

This paper is organized as follows. Section 2 provides a brief review of the literature related to sustainable SC, opportunism in SC, and revenue sharing mechanisms. Section 3 develops the models and related equilibrium analyses for the JSD. Section 4 conducts a numerical analysis to examine and compare the performance of three contractual arrangements of profit sharing, followed by the discussion of the managerial implications, research contributions, and limitations in Section 5.

\section{Literature Review}

As an attempt to integrate the economic and non-economic issues in a SC, sustainability has been recognized as one of the key research themes [23]. The literature has predominantly focused on what economic benefits individual SC members can gain by building a sustainable SC. For instance, Drumwrigt [24] pointed out that firms should pursue social responsibility and social benefit in the process of carrying out economic activities, such as purchasing, production, consumption, etc. Carter and Rogers [25] argued that economic, environmental, and social aspects (i.e., triple bottom line) should be strategically and simultaneously considered to improve overall SC performance, as well as the performance of each SC member. Hassini et al. [13] also emphasized not only the importance of minimizing negative environmental impact and maximizing positive social effect, but also achieving profit maximization to establish sustainable SC. More recently, Golicic and Smith [26] conducted a meta-analysis of the research published for more than 20 years in this domain and confirmed the positive and significant impacts of sustainable SC practices on all three dimensions of performance (market- , operational- , and accounting-based form performance).

Despite the strong research evidence on the contributions of supply chain sustainability, several studies questioned the direct linkage of sustainability and financial benefits and the implementation of JSD programs. First, it is unclear whether the financial benefits are directly attributable to SC sustainability practices, or are simply additional gains from pre-existing, non-sustainability capabilities. Narasimhan et al. [14], for instance, examined the companies certified by ISO 14001 prior to FSC certification and found those pre-certified ones reported less or no abnormal financial gains at the time of FSC certification. Markman and Krause [27] also pointed out eight oil companies in a list of "the 100 most sustainable firms", according to the 2015 Global 100 Index, and questioned the link between sustainability and corporate performance. The second concern of the research gap relates to a lack of knowledge concerning how to develop a sustainable SC. Pagell and Shevchenko [28] noted that much empirical research on sustainable SC tends to be "backward looking" in that it focused on what happened to a sustainable SC, rather than addressing how SCs can become more sustainable. This view was echoed by many subsequent studies, such as Touboulic and Walker [29] and Montabon et al. [30], that called for future research to provide more implementation-focused approaches toward a sustainable SC.

SC scholars have historically highlighted that SC members need to behave as a unified system (i.e., a part of centralized SC) to improve overall SC performance [31,32]. They brought up the notion "SC collaboration" as a means of developing a more sustainable SC, but there are not many suggestions 
as to how a company can design and implement such a collaboration with its counterpart [33]. One recent attempt was a case study by Crespin-Mazet and Dontenwill [34], which demonstrated how one gardening distributor implemented JSD by working with its small agricultural suppliers. Potential opportunism among SC members has been named as a key barrier to the success of JSD, which is a good example of the adage "everyone's responsibility is no one's responsibility" [35,36]. In this vein, Cheng and Sheu [37] found that opportunistic behavior between partners deteriorates the positive effect of relationship orientation on the quality of green SC strategy. Crespin-Mazet and Dontenwill [34] reported a successful example of offsetting partners' fears of opportunism by utilizing its existing bonds with activist/militant organizations, but obviously this is not a viable approach to all JSDs. Identifying and aligning incentives between SC members can prevent opportunistic behaviors and lead to collaborative projects for sustainability performance where companies share interests [38]. Extant SC literature recognizes revenue sharing as an important mechanism to safeguard against opportunistic behavior and bring about the intended outcomes (e.g., [39]), but does not offer guidance on how such revenue sharing is arranged and how it influences both SC members' economic benefit of JSD, such as increased consumer demand. For instance, Guo et al. [40] investigated the impact of a manufacturer's sustainability development effort on consumer demand under the assumption that only the manufacturer would subsidize the retailer's cost associated with sustainability development. You et al. [41] discussed the profit sharing structure between manufacturer and government with no consideration of a revenue sharing mechanism, assuming that only the government would provide subsidy to the manufacturer.

In the following section, we develop mathematical models for various JSD revenue sharing mechanisms. The term "sustainability" hereafter refers to both environmental and social aspects of the concept, which is consistent with recent literature (e.g., [40,42]).

\section{Models and Analyses}

A baseline model is defined as retailers and manufacturers making separate/non-coordinated pricing decisions so that we can examine whether the double marginalization in a decentralized $\mathrm{SC}$ can be removed by applying revenue sharing. We then show how the JSD efforts influence consumer demand, and associated costs are implemented in the model. Section 3.1 investigates the opportunistic behavior in JSD when there is no revenue sharing arrangement. A partial sharing (PS) arrangement is examined in Section 3.2 to see whether this sharing mechanism could reduce or remove the opportunistic behavior. Section 3.3 reviews whether the double marginalization is removed in PS by comparing the solutions under sequential game with those under simultaneous game (solving retailer's and manufacturer's problems simultaneously, under the assumption that the retailer and manufacturer are acting as a unified entity, which derives the first best solution that maximizes total channel profit). Finally, the equilibrium solutions of a full sharing (FS) mechanism are derived by applying the sequential game used in Section 3.1.

Similar to many previous studies, we consider a business setting with one manufacturer and one retailer [43]. Consumer demand (final demand) is assumed to be linear, taking the form of inverse demand, i.e., $Q(p)=\alpha-\beta p$, where $Q$ is quantity demanded and $p$ is unit retail price. $\alpha$ and $\beta$, respectively, represent market size and sensitivity coefficient (positive constants, i.e., $\alpha, \beta>0$ ) $[44,45]$. Accordingly, a baseline model is developed as below:

$$
\Pi_{r}^{B}=\underbrace{\left(p-w-c_{r}\right)}_{\begin{array}{c}
\text { Retailer's unit } \\
\text { profit margin }
\end{array}} \underbrace{Q(p)}_{\begin{array}{c}
\text { Final } \\
\text { demand }
\end{array}}
$$




$$
\begin{gathered}
\Pi_{m}^{B}=\underbrace{\left(w-c_{m}\right)}_{\begin{array}{c}
\text { Manufacturer's } \\
\text { unit profit margin }
\end{array}} Q(p) \\
\Pi_{\text {total }}^{B}=\Pi_{r}^{B}+\Pi_{m}^{B}=\underbrace{\left(p-c_{r}-c_{m}\right)}_{\text {SC's unit profit margin }} Q(p)
\end{gathered}
$$

where $w$ is wholesale price, and $c_{r}$ and $c_{m}$ are costs of retailer and manufacturer (i.e., product and/or material handling and manufacturing costs), respectively. Note that subscripts $r$ and $m$, respectively, represent retailer and manufacturer, and superscript $B$ represents baseline model. Equations (1)-(3) represent retailer's, manufacturer's, and total channel profit functions, respectively. We first consider a unit profit margin sharing mechanism (a derivative of revenue sharing structure) to remove a double marginalization effect by setting $p-w-c_{r}=\Theta\left(w-c_{m}\right)\left(\theta\left(p-c_{r}-c_{m}\right)=p-w-c_{r}\right.$ and $(1-\theta)\left(p-c_{r}-c_{m}\right)=w-c_{m}$ thus, $p-w-c_{r}=\Theta\left(w-c_{m}\right)$, where $\left.\Theta=\frac{\theta}{1-\theta}\right)$, where $\Theta$ is positive constant, i.e., retailer's unit profit $p-w-c_{r}$ is manufacturer's unit profit $w-c_{m}$ times $\Theta$.

Proposition 1. Double marginalization will be removed under the unit profit margin sharing mechanism.

Proof. See the Appendix A.

Proposition 1 shows that we can initially remove the negative effect of potential double marginalization on channel profit by a certain contractual arrangement, i.e., unit profit margin sharing mechanism between manufacturer and retailer. Under this arrangement, decentralized and centralized SC generate the same economic performance (i.e., the same channel profit), so that we can clearly identify the sustainability development effect on SC members' and the overall SC profits when we implement the sustainability-related factors in the model.

Now, we consider the sustainability development effect that influences consumer (i.e., retailer's customer) demand, as well as market size and price sensitivity. There are three types of relationships between sustainability development effort and SC member's financial performance studied in the literature [46]: (i) positive correlation; (ii) negative correlation; and (iii) irrelevant. First, we implement the positive correlation in the model, i.e., the positive effect of a sustainability development effort on consumer demand $Q$ (additive impact) as follows [47]:

$$
Q(p, \eta)=\alpha-\beta p+k \cdot \eta
$$

where $k$ is an impact of sustainability development effort level $\eta$ of an organization $(k, \eta>0)$. The revised demand function implies that the higher the sustainability development effort an enterprise makes, the greater its product market demand, i.e., sustainability development effort will positively influence demand [48]. We further re-examine the demand function in Equation (4) from the SC perspective. Since manufacturer and retailer can make a joint sustainability effort, the impact of sustainability development by the entire SC on consumer demand $S$ can be expressed as follows:

$$
S\left(\eta_{m}, \eta_{r}\right)=k_{m} \eta_{m}+k_{r} \eta_{r}
$$

where $k$ implies relative weight on SC member's sustainability development effort. Note that $k_{m}, k_{r}>0$. Accordingly, consumer demand with the consideration of JSD can be expressed as:

$$
Q\left(p, \eta_{m}, \eta_{r}\right)=\alpha-\beta p+k_{m} \eta_{m}+k_{r} \eta_{r}
$$

However, sustainability development efforts could reduce manufacturer's and retailer's profits because of the associated development costs. Such costs may exponentially increase with the increase in sustainability development effort (i.e., diminishing effect of investment), as follows [49-51]: 


$$
C_{m}^{s}=\frac{\lambda_{m} \eta_{m}^{2}}{2} \text { and } C_{r}^{s}=\frac{\lambda_{r} \eta_{r}^{2}}{2}
$$

where $\lambda_{i} / 2, i \in\{m, r\}$, represents cost coefficient of fulfilling a certain level of sustainability development effort, $\lambda_{i}>0$. When the gain (additional profit) from increased consumer demand is offset by increased cost, the relationship between sustainability and profit can be perceived of as irrelevant, which will be addressed in the following profit functions of retailer and manufacturer, by implementing Equations (6) and (7).

\subsection{Sequential Game without Sharing Mechanism}

In this section, we investigate a sequential non-cooperative structure of the decision-making process without any sharing mechanisms. The manufacturer is the first mover on sustainability development and the retailer is considered as the follower, which is a common structure of the manufacturer-retailer relationship (e.g., [52]). In this structure, the manufacturer first decides its own sustainability development effort level and wholesale price, and the retailer then decides on the level of its own sustainability development effort and retail price. In accordance with the assumptions (regarding additive effect of JSD on consumer demand and associated costs), profit functions of manufacturer (Equation (8)), retailer (Equation (9)), and the whole SC system (sum of retailer's and manufacturer's profits) (Equation (10)) can be expressed as:

$$
\begin{gathered}
\Pi_{r}^{B S}=\left(p-w-c_{r}\right)\left(\alpha-\beta p+k_{m} \eta_{m}+k_{r} \eta_{r}\right)-\frac{\lambda_{r} \eta_{r}{ }^{2}}{2} \\
\Pi_{m}^{B S}=\left(w-c_{m}\right)\left(\alpha-\beta p+k_{m} \eta_{m}+k_{r} \eta_{r}\right)-\frac{\lambda_{m} \eta_{m}{ }^{2}}{2} \\
\Pi_{\text {total }}^{B S}=\Pi_{r}^{B S}+\Pi_{m}^{B S}=\left[p-\left(c_{r}+c_{m}\right)\right]\left(\alpha-\beta p+k_{m} \eta_{m}+k_{r} \eta_{r}\right)-\frac{\lambda_{r} \eta_{r}{ }^{2}}{2}-\frac{\lambda_{m} \eta_{m}{ }^{2}}{2}
\end{gathered}
$$

Note that superscript $B S$ represents "baseline model with the consideration of sustainability development". Based on the profit functions in Equations (8) and (9), we can derive the following proposition that describes equilibrium decisions, including manufacturer's and retailer's sustainability development effort levels and prices.

Proposition 2. In the Stackelberg (sequential) model without sharing mechanism, the manufacturer's equilibrium sustainability development effort level (Equation (11)) and wholesale price (Equation (12)), and the retailer's equilibrium sustainability development effort level (Equation (13)) and retail price (Equation (14)) are given by:

$$
\begin{gathered}
\eta_{m}^{B S *}=k_{m} \lambda_{r}{ }^{2} \beta\left[\alpha-\beta\left(c_{m}+c_{r}\right)\right] \Psi^{B S} \\
w^{B S *}=\left[\beta c_{m} k_{r}{ }^{2} \lambda_{m} \lambda_{r}-\beta \lambda_{r}{ }^{2}\left[c_{m} k_{m}{ }^{2}-2 \beta\left(c_{m}-c_{r}\right) \lambda_{m}-2 \alpha \lambda_{m}\right]-c_{m} k_{r}{ }^{4} \lambda_{m}\right] \Psi^{B S} \\
\eta_{r}^{B S *}=k_{r} \lambda_{m}\left(k_{r}{ }^{2}+\beta \lambda_{r}\right)\left[\alpha-\beta\left(c_{m}+c_{r}\right)\right] \Psi^{B S} \\
p^{B S *}=\left[\alpha k_{r}{ }^{2} \lambda_{m} \lambda_{r}-\beta \lambda_{r}{ }^{2}\left[\left(c_{m}+c_{r}\right) k_{m}{ }^{2}-\beta\left(c_{m}+c_{r}\right) \lambda_{m}-3 \alpha \lambda_{m}\right]-\left(c_{m}+c_{r}\right) k_{r}{ }^{4} \lambda_{m}\right] \Psi
\end{gathered}
$$

where $\Psi^{B S}=\frac{1}{\left(\beta \lambda_{r}-k_{r}^{2}\right) k_{r}{ }^{2} \lambda_{m}+\beta\left(4 \beta \lambda_{m}-k_{m}{ }^{2}\right) \lambda_{r}{ }^{2}}$.

Proof. See the Appendix A.

Using Proposition 2, we can derive an interesting result. Intuitively, the manufacturer will increase its sustainability development effort as the impact of manufacturer's effort $k_{m}$ increases. It is easily shown that $\partial \eta_{m}^{B S *} / \partial k_{m}=\beta \lambda_{r}{ }^{2}\left[\alpha-\beta\left(c_{m}+c_{r}\right)\right]\left[\left(\beta \lambda_{r}-k_{r}{ }^{2}\right) k_{r}{ }^{2} \lambda_{m}+\beta\left(4 \beta \lambda_{m}+k_{m}{ }^{2}\right) \lambda_{r}{ }^{2}\right]\left(\Psi^{B S}\right)^{2}>0$ 
when $\eta_{m}^{B S *}>0$, which implies that $\eta_{m}^{B S *}$ is always increasing in $k_{m}$, since $\eta_{m}^{B S *}>0$ which implies that $\Psi^{B S}>0$, thus $\left(\beta \lambda_{r}-k_{r}^{2}\right) k_{r}^{2} \lambda_{m}+\beta\left(4 \beta \lambda_{m}+k_{m}^{2}\right) \lambda_{r}^{2}>0$.

However, $\partial \eta_{m}^{B S *} / \partial k_{r}=-2 \beta k_{m} k_{r} \lambda_{m} \lambda_{r}{ }^{2}\left[\alpha-\beta\left(c_{m}+c_{r}\right)\right]\left(\beta \lambda_{r}-2 k_{r}{ }^{2}\right)\left(\Psi^{B S}\right)^{2}$, which implies that $\eta_{m}^{B S *}$ is increasing in $k_{r}$ if $\beta \lambda_{r} / 2<k_{r}{ }^{2}<2 \beta \lambda_{r}$ but decreasing in $k_{r}$ if $k_{r}{ }^{2}<\beta \lambda_{r} / 2$. This means that, when the impact of retailer's effort $k_{r}$ is low, the increase of $k_{r}$ triggers manufacturer's opportunistic behavior, i.e., manufacturer will decrease its effort as the impact of retailer's effort increases. On the other hand, when the impact of retailer's effort $k_{r}$ is high, the manufacturer will increase its effort as $k_{r}$ increases as shown in Figure 1a. In this case, $\partial \eta_{r}^{B S *} / \partial k_{r}\left(\partial \eta_{r}^{B S *} / \partial k_{r}=\right.$ $\left.\left[\lambda_{m}\left[\alpha-\beta\left(c_{m}+c_{r}\right)\right]\left[\left(4 \beta \lambda_{r}+k_{r}{ }^{2}\right) k_{r}{ }^{2}-\beta^{2} \lambda_{r}{ }^{2}\right] k_{r}{ }^{2} \lambda_{m}+\left[\beta \lambda_{r}+3 k_{r}{ }^{2}\right] \beta\left(4 \beta \lambda_{m}-k_{m}{ }^{2}\right) \lambda_{r}{ }^{2}\right]\left(\Psi^{B S}\right)^{2}\right) \quad$ is more likely to be positive when $k_{m}$ is relatively low, which means the retailer will increase its effort in sustainability development as $k_{r}$ increases. Thus, the manufacturer will become more cooperative with the retailer (in terms of JSD) when $k_{r}$ is relatively high. Similarly, we can show that $\partial \eta_{r}^{B S *} / \partial k_{m}=2 \beta k_{m} k_{r} \lambda_{m} \lambda_{r}^{2}\left[\alpha-\beta\left(c_{m}+c_{r}\right)\right]\left(k_{r}{ }^{2}+\beta \lambda_{r}\right)\left(\Psi^{B S}\right)^{2}>0$ when $\eta_{r}^{B S *}>0$ (since $\eta_{r}^{B S *}>0 \Rightarrow \Psi^{B S}>0$ ), which implies that the retailer will increase its own effort as the impact of manufacturer's effort $k_{m}$ increases. As a result, as illustrated in Figure 1b, the retailer will always be cooperative with the manufacturer in JSD, since the manufacturer will increase its effort as $k_{m}$ increases.

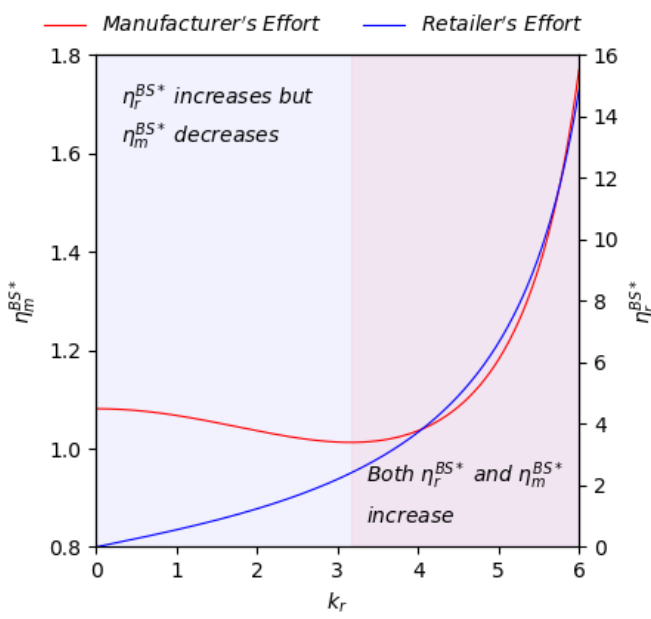

(a)

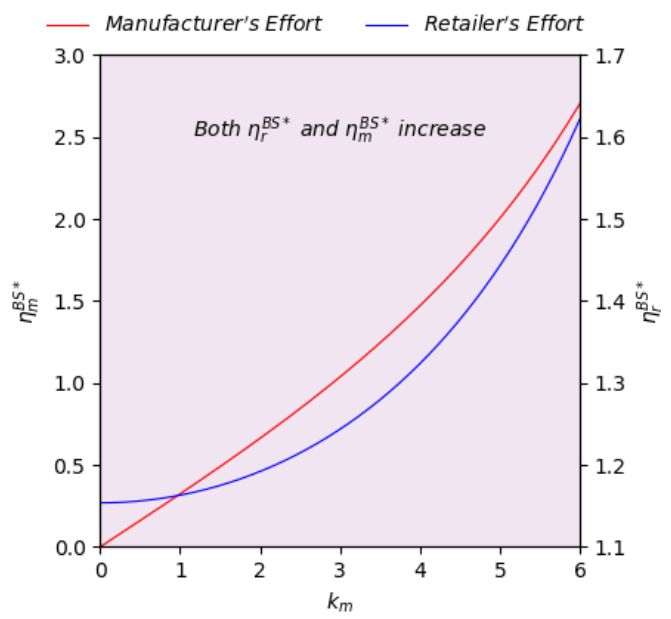

(b)

Figure 1. Sequential game with sharing mechanism: (a) $\eta_{m}^{B S *}$ and $\eta_{r}^{B S *}$ over $k_{r}$ at $\alpha=100, \beta=10$, $c_{m}=5.0, c_{r}=1.0, \lambda_{m}=3.0, \lambda_{r}=2.0$, and $k_{m}=3.0$; and (b) $\eta_{m}^{B S *}$ and $\eta_{r}^{B S *}$ over $k_{m}$ at $\alpha=100, \beta=10$, $c_{m}=5.0, c_{r}=1.0, \lambda_{m}=3.0, \lambda_{r}=2.0$, and $k_{r}=2.0$.

\subsection{Sequential Game with Partial Sharing Mechanism}

In the literature, revenue sharing (unit profit margin sharing structure in this study) is used to coordinate the JSD in a SC (e.g., [39]). In this case, manufacturers' and retailers' JSD effort is coordinated without sharing the fixed costs [53]. We define the scenario of profit sharing (with no fixed cost sharing) as $P S$ structure with the unit profit margin structure used in Proposition 1, i.e., $p-w-c_{r}=\Theta\left(w-c_{m}\right)$ :

$$
\begin{gathered}
\Pi_{r}^{P S}=\theta\left[p-\left(c_{r}+c_{m}\right)\right]\left[\alpha-\beta p+k_{m} \eta_{m}+k_{r} \eta_{r}\right]-\frac{\lambda_{r} \eta_{r}{ }^{2}}{2} \\
\Pi_{m}^{P S}=(1-\theta)\left[p-\left(c_{r}+c_{m}\right)\right]\left[\alpha-\beta p+k_{m} \eta_{m}+k_{r} \eta_{r}\right]-\frac{\lambda_{m} \eta_{m}^{2}}{2} \\
\Pi_{\text {total }}^{P S}=\Pi_{r}^{P S}+\Pi_{m}^{P S}=\left[p-\left(c_{r}+c_{m}\right)\right]\left[\alpha-\beta p+k_{m} \eta_{m}+k_{r} \eta_{r}\right]-\frac{\lambda_{r} \eta_{r}^{2}}{2}-\frac{\lambda_{m} \eta_{m}{ }^{2}}{2}
\end{gathered}
$$


where $\theta$ is retailer's portion and $1-\theta$ is manufacturer's portion of unit profit margin.

Based on the retailer's and manufacturer's profit functions, respectively, in Equations (15) and (16), and the total channel profit in Equation (17), we can derive the following proposition that describes equilibrium decisions including manufacturer and retailer in terms of sustainability development effort levels and prices under the PS mechanism.

Proposition 3. In the PS mechanism, the manufacturer's equilibrium sustainability development effort level (Equation (18)) and wholesale price (Equation (19)), and the retailer's equilibrium sustainability development effort level (Equation (20)) and retail price (Equation (21)) are given by:

$$
\begin{gathered}
\eta_{m}^{P S *}=2 k_{m} \lambda_{r}^{2} \beta(1-\theta) \Psi^{P S} \\
w^{P S *}=\lambda_{r} \lambda_{m}\left(2 \beta \lambda_{r}-k_{r}^{2} \theta\right)(1-\theta) \Psi^{P S}+c_{m} \\
\eta_{r}^{P S *}=k_{r} \lambda_{m} \theta\left(2 \beta \lambda_{r}-k_{r}^{2} \theta\right) \Psi^{P S} \\
p^{P S *}=\lambda_{r} \lambda_{m}\left(2 \beta \lambda_{r}-k_{r}^{2} \theta\right) \Psi^{P S}+c_{r}+c_{m}
\end{gathered}
$$

where $\Psi^{P S}=\frac{\alpha-\left(c_{r}+c_{m}\right) \beta}{\lambda_{m}\left(2 \beta \lambda_{r}-k_{r}^{2} \theta\right)^{2}-2 \beta k_{m}^{2} \lambda_{r}{ }^{2}(1-\theta)}$.

Proof. See the Appendix A.

It can easily be shown that $\partial \eta_{m}^{P S *} / \partial k_{m}=\frac{2 \beta(1-\theta) \lambda_{r}{ }^{2}\left[\lambda_{m}\left(2 \beta \lambda_{r}-k_{r}{ }^{2} \theta\right)^{2}+2 \beta k_{m}{ }^{2} \lambda_{r}{ }^{2}(1-\theta)\right]}{\alpha-\beta\left(c_{m}+c_{r}\right)}\left(\Psi^{P S}\right)^{2}>0$, since $\eta_{m}^{P S *}>0$ which implies that $\Psi^{P S}>0$, thus $\lambda_{m}\left(2 \beta \lambda_{r}-k_{r}^{2} \theta\right)^{2}+2 \beta k_{m}{ }^{2} \lambda_{r}{ }^{2}(1-\theta)>0$. This implies that the manufacturer will increase its effort level as the impact of the manufacturer's sustainability development effort $k_{m}$ increases. It can also easily be shown that $\partial \eta_{m}^{P S *} / \partial k_{r}=$ $\frac{8 \beta \theta(1-\theta) k_{m} k_{r} \lambda_{m} \lambda_{r}^{2}\left(2 \beta \lambda_{r}-k_{r}^{2} \theta\right)}{\alpha-\beta\left(c_{m}+c_{r}\right)}\left(\Psi^{P S}\right)^{2}>0$, since $\eta_{m}^{P S *}>0 \Rightarrow \Psi P S>0$ and $2 \beta \lambda_{r}-k_{r}^{2} \theta>0$. This implies that the manufacturer will increase its effort level as the impact of the retailer's sustainability development effort $k_{r}$ increases. Therefore, manufacturer's opportunistic behavior can be removed under PS.

Proposition 4. When both retailer's and manufacturer's sustainability effort levels are nonnegative under PS, i.e., $\eta_{r}^{P S *}>0$ and $\eta_{m}^{P S *}>0$ : (i) wholesale price under PS is higher than that with no sharing, i.e., $w^{P S *}>w^{B *}$; (ii) retail price under $P S$ is higher than that with no sharing, i.e., $p^{P S *}>p^{B *}$; and (iii) consumer demand under $P S$ is higher than that with no sharing, i.e., $Q\left(p^{P S *}, \eta_{r}^{P S *}, \eta_{m}^{P S *}\right)>Q\left(p^{B *}\right)$.

Proof for Proposition 4. (i) We claim that

$$
w^{B *}-w^{P S *}=\left[k_{r}^{4} \theta^{2} \lambda_{m}-2 \beta \lambda_{r}\left[k_{r}{ }^{2} \theta \lambda_{m}+k_{m}{ }^{2}(1-\theta) \lambda_{r}\right]\right]\left[\alpha-\left(c_{r}+c_{m}\right) \beta\right]>0
$$

By definition, $\alpha-\left(c_{r}+c_{m}\right) \beta>0$, since $c_{r}+c_{m}<p$. Thus, by simple algebra, we can derive that

$$
\left[\frac{k_{r}^{2} \lambda_{m} \theta}{k_{r}^{2} \lambda_{m} \theta+k_{m}^{2} \lambda_{r}(1-\theta)}\right] k_{r}^{2} \theta>2 \lambda_{r} \beta
$$

From Equations (15)-(21), we can also derive a necessary condition (non-negative demand), i.e., $\alpha-\beta p^{P S *}+k_{m} \eta_{m}^{P S *}+k_{r} \eta_{r}^{P S *}>0$. This condition can be simplified as $k_{r}^{2} \theta<2 \beta \lambda_{r}$, since $\Psi^{P S}>0$ from Equations (18) and (20) when $\eta_{r}^{P S *}>0$ and/or $\eta_{m}^{P S *}>0$. However, $\frac{k_{r}{ }^{2} \lambda_{m} \theta}{k_{r}{ }^{2} \lambda_{m} \theta+k_{m}{ }^{2} \lambda_{r}(1-\theta)}<1$, because $k_{r}{ }^{2} \lambda_{m} \theta, k_{m}{ }^{2} \lambda_{r}(1-\theta)>0$. Therefore, Equation (23) is not true, which means that $w^{B *}-w^{P S *}<0 \Leftrightarrow w^{P S *}>w^{B *}$ (by contradiction). 
(ii) Similarly, we can show that $p^{B *}-p^{P S *}<0 \Leftrightarrow p^{P S *}>p^{B *}$, since retail price is proportional to wholesale price.

(iii) Moreover, we can simplify $Q\left(p^{B *}\right)-Q\left(p^{P S *}, \eta_{r}^{P S *}, \eta_{m}^{P S *}\right)$ as follows:

$$
\frac{1}{2}\left[\alpha-\left(c_{r}+c_{m}\right) \beta\right]\left[\lambda_{m}\left(k_{r}{ }^{2} \theta+2 \beta \lambda_{r}\right)\left(k_{r}{ }^{2} \theta-2 \beta \lambda_{r}\right)-2 \beta \lambda_{r} k_{m}{ }^{2} \lambda_{r}{ }^{2}(1-\theta)\right]
$$

It is true that $k_{r}^{2} \theta-2 \beta \lambda_{r}<0$ when demand is non-negative. Therefore, Equation (24) becomes negative, which implies that $Q\left(p^{P S *}, \eta_{r}^{P S *}, \eta_{m}^{P S *}\right)>Q\left(p^{B *}\right)$.

Proposition 4 shows that the JSD with PS mechanism in the manufacturer-retailer relationship will increase not only the wholesale price but also the retail price. However, more consumers might be willing to pay more for the product produced in the responsible SC, i.e., demand will increase. We can observe that as the retailer's portion of unit profit margin $\theta$ increases, the difference between $Q\left(p^{B *}\right)$ and $Q\left(p^{P S *}, \eta_{r}^{P S *}, \eta_{m}^{P S *}\right)$ decreases from Equation (24), i.e., the absolute value of consumer demand under $B$ and that under $P S,\left|Q\left(p^{B *}\right)-Q\left(p^{P S *}, \eta_{r}^{P S *}, \eta_{m}^{P S *}\right)\right|$, decreases. Thus, we need to investigate the impact of $\theta$ on retailer's and manufacturer's JSD decisions, since consumer demand will be influenced by retail price and sustainability development efforts made by both retailer and manufacturer.

Proposition 5. When both retailer's and manufacturer's sustainability effort levels are nonnegative under PS, i.e., $\eta_{r}^{P S *}>0$ and $\eta_{m}^{P S *}>0$,

a. Both $\eta_{r}^{P S *}$ and $\eta_{m}^{P S *}$ are increasing in $\theta$, when $\Theta_{\eta_{r}}^{P S *} \cap \Theta_{\eta_{m}}^{P S *}$

b. $\quad \eta_{r}^{P S *}$ is increasing but $\eta_{m}^{P S *}$ is decreasing in $\theta$, when $\Theta_{\eta_{r}}^{P S *} \cap\left(\Theta_{\eta_{m}}^{P S *}\right)^{C}$

c. $\quad \eta_{r}^{P S *}$ is decreasing but $\eta_{m}^{P S *}$ is increasing in $\theta$, when $\left(\Theta_{\eta_{r}}^{P S *}\right)^{C} \cap \Theta_{\eta_{m}}^{P S *}$

d. Both $\eta_{r}^{P S *}$ and $\eta_{m}^{P S *}$ are decreasing in $\theta$, when $\left(\Theta_{\eta_{r}}^{P S *}\right)^{C} \cap\left(\Theta_{\eta_{m}}^{P S *}\right)^{C}$,

where $\Theta_{\eta_{r}}^{P S *}=\left[0, \min \left\{\max \left\{0, \min \theta_{\eta_{r}}^{P S *}\right\}, 1\right\}\right], \Theta_{\eta_{m}}^{P S *}=\left[0, \min \left\{\max \left\{0,2-\frac{2 \beta \lambda_{r}}{k_{r}{ }^{2}}\right\}, 1\right\}\right]$ and $\min \theta_{\eta_{r}}^{P S *}=$ $\frac{k_{r} \lambda_{r}\left(2 \beta \lambda_{m}-k_{m}^{2}\right)-k_{m} \lambda_{r} \sqrt{\left(2 \beta \lambda_{m}-k_{m}^{2}\right)\left(2 \beta \lambda_{r}-k_{r}^{2}\right)}}{k_{r}\left(k_{r}^{2} \lambda_{m}-k_{m}^{2} \lambda_{r}\right)}$.

Proof for Proposition 5. $\frac{\partial \eta_{r}^{P S *}}{\partial \theta}=\underbrace{\frac{2 \beta k_{r} \lambda_{r} \lambda_{m}}{\alpha-\left(c_{r}+c_{m}\right) \beta}\left(\Psi^{P S}\right)^{2}\left[\lambda_{m}\left(2 \beta \lambda_{r}-k_{r}^{2} \theta\right)^{2}-k_{m}{ }^{2} \lambda_{r}\left[2 \beta \lambda_{r}-k_{r}{ }^{2} \theta(2-\theta)\right]\right]}_{\text {part } 1}$ part 2

We know that Part 1 is positive, since non-negative demand condition when $\eta_{r}^{P S *}>0$ and $\eta_{m}^{P S *}>0$. However, Part 2 could be positive or negative. The first derivative of Part 2 with respect to $\theta$ is

$$
-2 k_{r}^{2}\left[\frac{\lambda_{m}\left(2 \beta \lambda_{r}-k_{r}^{2} \theta\right)^{2}}{2 \beta \lambda_{r}-k_{r}^{2} \theta}-\frac{2 \beta k_{m}{ }^{2} \lambda_{r}{ }^{2}(1-\theta)}{2 \beta \lambda_{r}}\right]
$$

However, $\lambda_{m}\left(2 \beta \lambda_{r}-k_{r}^{2} \theta\right)^{2}-2 \beta k_{m}^{2} \lambda_{r}^{2}(1-\theta)>0$ and $2 \beta \lambda_{r}-k_{r}^{2} \theta>0$ (because of non-negative demand condition) when $\Psi^{P S}>0$. Thus, Equation (25) is negative. Solving Part 2 for $\theta$ gives

$$
\theta_{\eta_{r}}^{P S *}=\frac{k_{r} \lambda_{r}\left(2 \beta \lambda_{m}-k_{m}^{2}\right) \pm k_{m} \lambda_{r} \sqrt{\left(2 \beta \lambda_{m}-k_{m}^{2}\right)\left(2 \beta \lambda_{r}-k_{r}^{2}\right)}}{k_{r}\left(k_{r}^{2} \lambda_{m}-k_{m}^{2} \lambda_{r}\right)}
$$

Thus, when $\theta \in\left[0, \min \left\{\max \left\{0, \min \theta_{\eta_{r}}^{P S *}\right\}, 1\right\}\right]=\Theta_{\eta_{r}}^{P S *}, \eta_{r}^{P S *}$ is increasing in $\theta$. Note that when $\theta$ is an arbitrary big number, i.e., $\theta \gg 1$, Equation (25) could be positive, but out of our area of interest. 
Moreover, $\frac{\partial \eta_{m}^{P S *}}{\partial \theta}=-\underbrace{\frac{2 \beta k_{m} \lambda_{m} \lambda_{r}{ }^{2}\left(2 \beta \lambda_{r}-k_{r}{ }^{2} \theta\right)}{\alpha-\left(c_{r}+c_{m}\right) \beta}\left(\Psi^{P S}\right)^{2}}_{\text {part } 1} \underbrace{\left[2 \beta \lambda_{r}-k_{r}{ }^{2}(2-\theta)\right]}_{\text {part } 2}$. We know that Part 1 is positive, since the non-negative demand condition when $\eta_{r}^{P S *}>0$ and $\eta_{m}^{P S *}>0$. However, Part 2 could be positive or negative (increasing in $\theta$ ). Solving Part 2 for $\theta$ gives

$$
\theta=2-\frac{2 \beta \lambda_{r}}{k_{r}^{2}}
$$

Thus, $\eta_{m}^{P S *}$ is increasing in $\theta$ when $\theta \in\left[0, \min \left\{\max \left\{0,2-\frac{2 \beta \lambda_{r}}{k_{r}{ }^{2}}\right\}, 1\right\}\right]=\Theta_{\eta_{m}}^{P S *}$, since $0 \leq \theta \leq 1$. Therefore: (i) when $\Theta_{\eta_{r}}^{P S *} \cap \Theta_{\eta_{m}}^{P S *}$, both $\eta_{r}^{P S *}$ and $\eta_{m}^{P S *}$ are increasing in $\theta$; (ii) when $\Theta_{\eta_{r}}^{P S *} \cap\left(\Theta_{\eta_{m}}^{P S *}\right)^{C}$, $\eta_{r}^{P S *}$ is increasing but $\eta_{m}^{P S *}$ is decreasing in $\theta$; and (iii) when $\left(\Theta_{\eta_{r}}^{P S *}\right)^{C} \cap \Theta_{\eta_{m}}^{P S *}, \eta_{r}^{P S *}$ is decreasing but $\eta_{m}^{P S *}$ is increasing in $\theta$, and (iv) when $\left(\Theta_{\eta_{r}}^{P S *}\right)^{C} \cap\left(\Theta_{\eta_{m}}^{P S *}\right)^{C}$, both $\eta_{r}^{P S *}$ and $\eta_{m}^{P S *}$ are decreasing in $\theta$

Figure 2 summarizes the results derived in Proposition 5. Figure 2 show the manufacturer's and retailer's efforts over the retailer's portion of unit profit, $\theta$, at different impact of retailer's effort, $k_{r}$. As we can expect, $\theta$ increases as retailer's effort $\eta_{r}^{P S *}$ increases while $\eta_{m}^{P S *}$ decreases when $k_{r}$ is low (i.e., $k_{r}=1.0$ ). As the manufacturer's portion decreases (i.e., $\theta$ increases), its ability to afford the cost for sustainability development will decrease (whereas retailer's ability will increase). However, when $k_{r}$ is high (i.e., $k_{r}=5.0$ ), the increase in $\theta$ could be recognized as the concept of efficiently increased investment from the manufacturer's perspective, since it will increase consumer demand so that retailer's profit can be improved in this case (i.e., increased $\theta$ enables the retailer to increase its effort and the increased effort will be more effective in increasing consumer demand compared to the case where $k_{r}=1.0$ ). Thus, a manufacturer can increase its sustainability effort level when $\theta$ is not high. Moreover, when $k_{r}$ is very high (i.e., $k_{r}=6.0$ ), similar to the previous case where $k_{r}=5.0$, the manufacturer will be cooperative with the retailer in the sustainability development, i.e., $\eta_{m}^{P S *}$ increase until $\theta$ is not extremely high (in Proposition $5, \Theta_{\eta_{m}}^{P S_{*}}=\left[0, \min \left\{\max \left\{0,2-\frac{2 \beta \lambda_{r}}{k_{r}{ }^{2}}\right\}, 1\right\}\right]$ and $\frac{2 \beta \lambda_{r}}{k_{r}{ }^{2}}$ is decreasing as $k_{r}$ increases, thus manufacturer's cooperative behavior will be maintained over a wider range of $\theta$ at higher $k_{r}$ ).

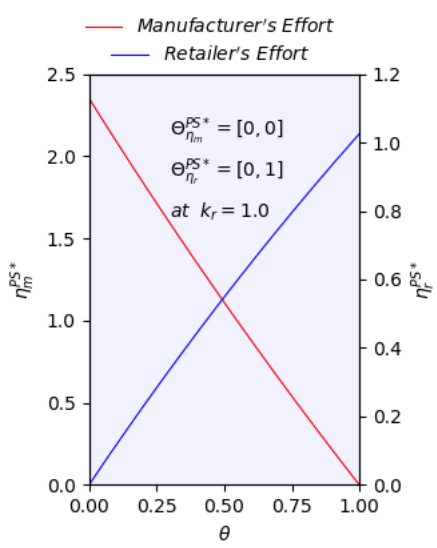

(a)

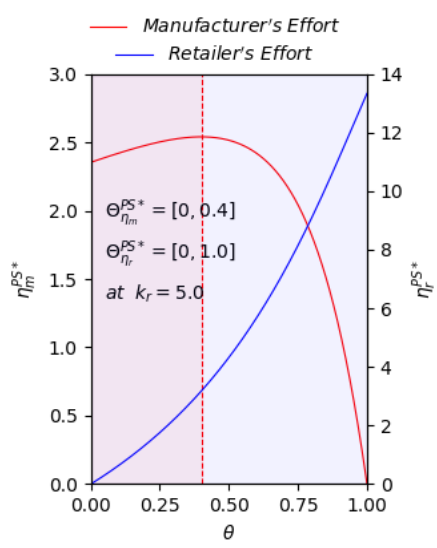

(b)

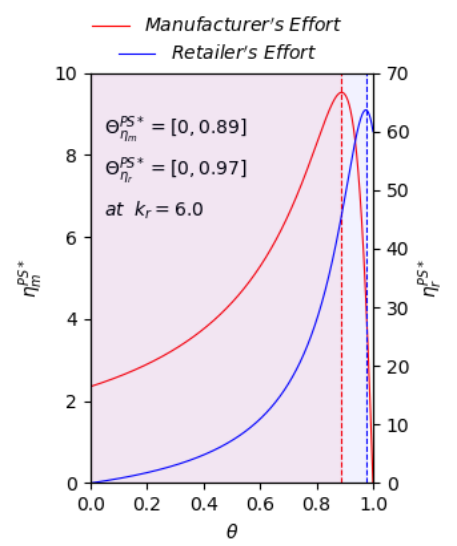

(c)

Figure 2. Sequential game with partial sharing mechanism: $\eta_{m}^{B S *}$ and $\eta_{r}^{B S *}$ over $\theta$ at $\alpha=100, \beta=10$, $c_{m}=5.0, c_{r}=1.0, \lambda_{m}=3.0, \lambda_{r}=2.0$, and $k_{m}=3.0$. (a) at $k_{r}=1.0,(\mathbf{b})$ at $k_{r}=5.0$, and (c) at $k_{r}=6.0$.

Note that, when $k_{r}=6.0$ and $\theta$ is extremely high $(\theta \geq 0.97)$, in Figure 2, retailer's effort will decrease as $\theta$ increases. It is because the cost for sustainability development is exponentially increasing. 
When $\theta$ is extremely high (from $\theta=0.89$ ) the manufacturer will decrease its effort and the retailer will also decrease its effort, since maintaining or increasing its effort will be too much burden as $\theta$ increases (manufacturer moves first). Soon after, the burden will be transferred to the retailer, thus the retailer will start decreasing its effort from $\theta=0.97$ (retailer follows), i.e., the retailer will decrease its effort to maintain or minimize the loss of its profit. Note that retailer's decreased effort at $k_{r}=6.0$ and extremely high $\theta(\theta \geq 0.97)$ is still higher than the effort at $k_{r}=5.0$. It is very difficult to show both parties' decisions with closed form solutions because of the complexity of the profit functions and corresponding equilibrium solutions. Thus, in Section 4, we investigate both parties' profits in detail, using numerical experiments.

\subsection{Simultaneous Game with Partial Sharing Mechanism}

Here, we assume the sustainability efforts of both manufacturer and retailer influence consumer demand. Thus, Jeuland and Shugan's [53] argument, i.e., fixed cost sharing does not affect SC coordination, does not hold in this study. To verify the effect of fixed cost sharing in SC coordination, we first provide equilibrium decisions on prices and sustainability development efforts by solving Equation (17) from the centralized SC structure perspective, i.e., $\max _{p \geq 0, w \geq 0, \eta_{r} \geq 0, \eta_{m} \geq 0}\left\{\Pi_{\text {total }}^{P S}=\Pi_{\text {total }}^{C P S}\right\}$. We denote that superscript CPS is centralized partial sharing mechanism. Note that we solve simultaneous game for $P S$ in this section to verify if it still can remove double marginalization.

Proposition 6. In the centralized structure with PS, the manufacturer's equilibrium sustainability development effort level (Equation (28)) and wholesale price (Equation (29)), and the retailer's equilibrium sustainability development effort level (Equation (30)) and retail price (Equation (31)) are given by:

$$
\begin{gathered}
\eta_{m}^{C P S *}=k_{m} \lambda_{r} \Psi^{C P S} \\
w^{C P S *}=\lambda_{r} \lambda_{m}(1-\theta) \Psi^{C P S}+c_{m} \\
\eta_{r}^{C P S *}=k_{r} \lambda_{m} \Psi^{C P S} \\
p^{C P S *}=\lambda_{r} \lambda_{m} \Psi^{C P S}+c_{r}+c_{m}
\end{gathered}
$$

where $\Psi^{C P S}=\frac{\alpha-\left(c_{r}+c_{m}\right) \beta}{\lambda_{m}\left(2 \beta \lambda_{r}-k_{r}^{2}\right)-k_{m}^{2} \lambda_{r}}$.

Proof. See the Appendix A.

Proposition 7. (i) $\eta_{r}^{C P S *} \geq \eta_{r}^{P S *}$; (ii) $\eta_{m}^{C P S *} \geq \eta_{m}^{P S *}$; (iii) $p^{C P S *} \geq p^{P S *}$; (iv) $w^{C P S *} \geq w^{P S *}$; and (v) $Q\left(p^{C P S *}, \eta_{r}^{C P S *}, \eta_{m}^{C P S *}\right) \geq Q\left(p^{P S *}, \eta_{r}^{P S *}, \eta_{m}^{P S *}\right)$.

Proof for Proposition 7. (i) We claim that

$$
\eta_{r}^{C P S *} \geq \eta_{r}^{P S *} \Leftrightarrow k_{r} \lambda_{m} \frac{\alpha-\left(c_{r}+c_{m}\right) \beta}{\lambda_{m}\left(2 \beta \lambda_{r}-k_{r}^{2}\right)-k_{m}^{2} \lambda_{r}}>k_{r} \lambda_{m} \theta\left(2 \beta \lambda_{r}-k_{r}^{2} \theta\right) \frac{\alpha-\left(c_{r}+c_{m}\right) \beta}{\lambda_{m}\left(k_{r}^{2} \theta-2 \beta \lambda_{r}\right)^{2}-2 \beta k_{m}^{2} \lambda_{r}^{2}(1-\theta)}
$$

which can be simplified as $\lambda_{m}\left(2 \beta \lambda_{r}-k_{r}{ }^{2}\right) \underbrace{\left(1-\frac{1}{\theta}\right)}_{\text {Part } 1}-k_{m}{ }^{2} \lambda_{r} \underbrace{\left(1-\frac{2 \beta \lambda_{r}-2 \beta \lambda_{r} \theta}{2 \beta \lambda_{r}-k_{r}{ }^{2} \theta} \frac{1}{\theta}\right)}_{\text {Part } 2}-$ $k_{r}{ }^{2} \lambda_{m}\left(\frac{1}{\theta}-1\right)<0$ by simple algebra. The absolute value of Part 1 is always greater than Part 2 since $\frac{2 \beta \lambda_{r}-2 \beta \lambda_{r} \theta}{2 \beta \lambda_{r}-k_{r}{ }^{2} \theta}<1$, when Part 2 is negative. Moreover, $\lambda_{m}\left(2 \beta \lambda_{r}-k_{r}^{2}\right)>k_{m}{ }^{2} \lambda_{r}$ when $\eta_{r}^{\text {CPS* }} \geq 0$. Thus, it means the argument is true when Part 2 is negative, since Part 1 is always negative (because $0<\theta<1$ ). In addition, when Part 2 is positive, the second term is negative. Therefore, this argument is always true. 
(ii) We claim that

$$
\eta_{m}^{C P S *} \geq \eta_{m}^{P S *} \Leftrightarrow k_{m} \lambda_{r} \frac{\alpha-\left(c_{r}+c_{m}\right) \beta}{\lambda_{m}\left(2 \beta \lambda_{r}-k_{r}^{2}\right)-k_{m}^{2} \lambda_{r}}>k_{m} \lambda_{r}\left[2 \beta \lambda_{r}(1-\theta)\right] \frac{\alpha-\left(c_{r}+c_{m}\right) \beta}{\lambda_{m}\left(k_{r}^{2} \theta-2 \beta \lambda_{r}\right)^{2}-2 \beta k_{m}^{2} \lambda_{r}^{2}(1-\theta)}
$$

which can be simplified as $\frac{2 \beta \lambda_{r}-k_{r}^{2} \theta}{2 \beta \lambda_{r}-2 \beta \lambda_{r} \theta}\left(2 \beta \lambda_{r}-k_{r}^{2} \theta\right)>2 \beta \lambda_{r}-k_{r}^{2}$ by simple algebra. However, $\frac{2 \beta \lambda_{r}-k_{r}^{2} \theta}{2 \beta \lambda_{r}-2 \beta \lambda_{r} \theta}>1$, when $\eta_{m}^{C P S *} \geq 0$ and $2 \beta \lambda_{r}-k_{r}^{2} \theta>2 \beta \lambda_{r}-k_{r}^{2}$, since $0<\theta<1$. Therefore, $\eta_{m}^{C P S *} \geq \eta_{m}^{P S *}$ is true.

(iii) We claim that

$$
p^{C P S *} \geq p^{P S *} \Leftrightarrow \lambda_{r} \lambda_{m} \frac{\alpha-\left(c_{r}+c_{m}\right) \beta}{\lambda_{m}\left(2 \beta \lambda_{r}-k_{r}^{2}\right)-k_{m}^{2} \lambda_{r}}+c_{r}+c_{m}>\lambda_{r} \lambda_{m}\left(2 \beta \lambda_{r}-k_{r}^{2} \theta\right) \frac{\alpha-\left(c_{r}+c_{m}\right) \beta}{\lambda_{m}\left(k_{r}^{2} \theta-2 \beta \lambda_{r}\right)^{2}-2 \beta k_{m}^{2} \lambda_{r}^{2}(1-\theta)}+c_{r}+c_{m}
$$

which can be simplified as $\lambda_{m}\left(2 \beta \lambda_{r}-k_{r}^{2} \theta\right)-k_{m}{ }^{2} \lambda_{r} \frac{2 \beta \lambda_{r}-2 \beta \lambda_{r} \theta}{2 \beta \lambda_{r}-k_{r}{ }^{2} \theta}>\lambda_{m}\left(2 \beta \lambda_{r}-k_{r}{ }^{2}\right)-k_{m}{ }^{2} \lambda_{r}$ by simple algebra. However, $2 \beta \lambda_{r}-k_{r}^{2} \theta>2 \beta \lambda_{r}-k_{r}^{2}$ (since $0<\theta<1$ ) and $\frac{2 \beta \lambda_{r}-2 \beta \lambda_{r} \theta}{2 \beta \lambda_{r}-k_{r}{ }^{2} \theta}<1$. Therefore, the argument is always true.

(iv) Moreover, $w^{C P S *} \geq w^{P S *}$ because of the relationship between retail and wholesale price under the unit profit-sharing structure.

(v) Based on the results, we also claim that the demand under two structures has the following relationship,

$$
\begin{gathered}
Q\left(p^{C P S *}, \eta_{r}^{C P S *}, \eta_{m}^{C P S *}\right) \geq Q\left(p^{P S *}, \eta_{r}^{P S *}, \eta_{m}^{P S *}\right) \Leftrightarrow \alpha+\left[-\beta \lambda_{r} \lambda_{m}+k_{m}{ }^{2} \lambda_{r}+k_{r}{ }^{2} \lambda_{m}\right] \frac{\alpha-\left(c_{r}+c_{m}\right) \beta}{\lambda_{m}\left(2 \beta \lambda_{r}-k_{r}{ }^{2}-k_{m}{ }^{2} \lambda_{r}\right.}-\left(c_{r}+c_{m}\right) \beta \geq \\
\alpha+\left[-\beta \lambda_{r} \lambda_{m}\left(2 \beta \lambda_{r}-k_{r}^{2} \theta\right)+2 \beta k_{m}{ }^{2} \lambda_{r}{ }^{2}(1-\theta)+k_{r}{ }^{2} \lambda_{m} \theta\left(2 \beta \lambda_{r}-k_{r}{ }^{2} \theta\right)\right] \frac{\alpha-\left(c_{r}+c_{m}\right) \beta}{\lambda_{m}\left(2 \beta \lambda_{r}-k_{r}^{2} \theta\right)^{2}-2 \beta k_{m}{ }^{2} \lambda_{r}{ }^{2}(1-\theta)}-\left(c_{r}+c_{m}\right) \beta
\end{gathered}
$$

which can be simplified as

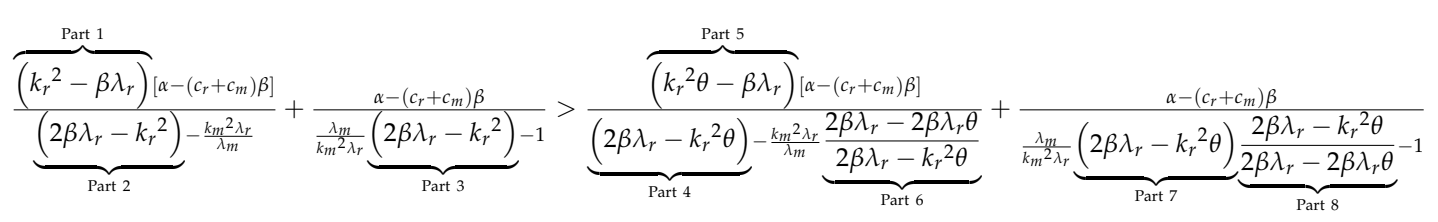

Part 1 is always greater than Part 5 and Part 2 is always less than Part 4 , since $0<\theta<1$. Moreover, Part 6 is always less than 1 , since $2 \beta \lambda_{r}>k_{r}{ }^{2}$ under equilibrium of centralized structure. Thus, the first term of LHS is greater than that of RHS. Similarly, Part 3 is always less than Part 7 and Part 8 is always greater than 1 , since $2 \beta \lambda_{r}>k_{r}{ }^{2}$ under equilibrium of centralized structure. Thus, the second term of LHS is always greater than that of RHS. Therefore, the argument is true.

Theoretically, the channel profit of SC under a centralized structure is always greater than or equal to the total profit of SC (sum of retailer's profit and manufacturer's profit) under decentralized structure, i.e., $\Pi_{\text {total }}^{C P S}\left(p^{C P S *}, \eta_{r}^{C P S *}, \eta_{m}^{C P S *}\right) \geq \Pi_{m}^{P S *}\left(p^{P S *}, \eta_{r}^{P S *}, \eta_{m}^{P S *}\right)+\Pi_{r}^{P S *}\left(p^{P S *}, \eta_{r}^{P S *}, \eta_{m}^{P S *}\right)$. However, it is highly likely that $\Pi_{\text {total }}^{C P S}\left(p^{C P S *}, \eta_{r}^{C P S *}, \eta_{m}^{C P S *}\right) \neq \Pi_{m}^{P S *}\left(p^{P S *}, \eta_{r}^{P S *}, \eta_{m}^{P S *}\right)+\Pi_{r}^{P S *}\left(p^{P S *}, \eta_{r}^{P S *}, \eta_{m}^{P S *}\right)$ because of Proposition 7, both parties' effort levels and prices are higher under CPS than under PS. It can be regarded as double marginalization that uncoordinated decisions lead to channel inefficiency because of the misaligned profit incentives [54]. It is interesting to note that double marginalization derived in this section, is different than that discussed in the literature. In the literature, the inefficiency will arise because retail price increases, so that consumer demand will decrease. Thus, total profit under a decentralized structure will be lower than channel profit under a centralized structure. However, in our case, the retail price will increase, but consumer demand will also increase because of increased sustainability development efforts made by both retailer and manufacturer. Interestingly, the increased retail price and consumer demand provide higher channel profit than under a centralized structure. This result confirms that there could be a better contractual arrangement than PS. 


\subsection{Sequential Game with Full Sharing Mechanism}

Based on the results derived in Section 3.3., i.e., the existence of double marginalization, we develop another sharing mechanism. In addition to the unit profit margin sharing, we implement the sharing of total fixed cost associated with JSD. We define this mechanism as FS as follows:

$$
\begin{gathered}
\Pi_{r}^{F S}=\theta\left[p-\left(c_{r}+c_{m}\right)\right]\left[\alpha-\beta p+k_{m} \eta_{m}+k_{r} \eta_{r}\right]-\gamma\left(\frac{\lambda_{r} \eta_{r}{ }^{2}}{2}+\frac{\lambda_{m} \eta_{m}{ }^{2}}{2}\right) \\
\Pi_{m}^{F S}=(1-\theta)\left[p-\left(c_{r}+c_{m}\right)\right]\left[\alpha-\beta p+k_{m} \eta_{m}+k_{r} \eta_{r}\right]-(1-\gamma)\left(\frac{\lambda_{r} \eta_{r}{ }^{2}}{2}+\frac{\lambda_{m} \eta_{m}{ }^{2}}{2}\right) \\
\Pi_{\text {total }}^{F S}=\Pi_{r}^{F S}+\Pi_{m}^{F S}=\left[p-\left(c_{r}+c_{m}\right)\right]\left[\alpha-\beta p+k_{m} \eta_{m}+k_{r} \eta_{r}\right]-\frac{\lambda_{r} \eta_{r}{ }^{2}}{2}-\frac{\lambda_{m} \eta_{m}{ }^{2}}{2}
\end{gathered}
$$

Equations (36)-(38), respectively, represent retailer's, manufacturer's, and total channel profit functions. We maintain the structure $p-w-c_{r}=\Theta\left(w-c_{m}\right)$ for unit profit margin sharing. In addition, total fixed costs associated with the JSD can be shared using parameter $\gamma$ and $1-\gamma$ that respectively represent the retailer's and manufacturer's portions of the total fixed cost. Therefore, FS can be seen as a more flexible sharing mechanism compared to $P S$.

Proposition 8. In the FS structure, the manufacturer's equilibrium sustainability development effort level (Equation (39)) and wholesale price (Equation (40)), and the retailer's equilibrium sustainability development effort level (Equation (41)) and retail price (Equation (42)) are given by:

$$
\begin{gathered}
\eta_{m}^{F S *}=\left[2 \beta \gamma^{2}(1-\theta) \lambda_{r}+(\gamma-\theta) \theta k_{r}^{2}\right]\left[\alpha-\beta\left(c_{m}+c_{r}\right)\right] k_{m} \Psi^{F S} \\
w^{F S *}=(1-\theta)\left[p^{F S *}-\left(c_{m}+c_{r}\right)\right]+c_{m} \\
\eta_{r}^{F S *}=2 \beta(1-\gamma) \gamma \theta k_{r} \lambda_{m}\left[\alpha-\beta\left(c_{m}+c_{r}\right)\right] \Psi^{F S} \\
p^{F S *}=\left[\begin{array}{l}
\theta\left(c_{m}+c_{r}\right) k_{r}^{2}\left[(\theta-\gamma) k_{m}^{2}-2 \beta(1-\gamma) \gamma \lambda_{m}\right] \\
-2 \beta \lambda_{r} \gamma^{2}\left[(1-\theta)\left(c_{m}+c_{r}\right) k_{m}^{2}-(1-\gamma)\left[\alpha+\beta\left(c_{m}+c_{r}\right)\right] \lambda_{m}\right]
\end{array}\right] \Psi^{F S}
\end{gathered}
$$

where $\Psi^{F S}=\frac{1}{2 \beta(1-\gamma) \gamma \lambda_{m}\left(2 \beta \gamma \lambda_{r}-\theta k_{r}{ }^{2}\right)-k_{m}^{2}\left[2 \beta \gamma^{2}(1-\theta) \lambda_{r}+(\gamma-\theta) \theta k_{r}^{2}\right]}$.

Proof. See the Appendix A.

Because of the complexity of profit functions and equilibrium solutions, as shown in Proposition 8, we investigate the performance of $F S$ in terms of each member's profit and channel profit by providing numerical experiments in Section 4.

\section{Numerical Experiments}

We carried out a series of numerical experiments to compare the effectiveness of three different contractual mechanisms SC practitioners may consider in pursuit of JSD: no sharing (BS), unit profit margin sharing (partial sharing; $P S$ ), and total profit and fixed cost sharing (full sharing; FS). First, we investigate the effectiveness of $P S$ by comparing with $B S$. Intuitively, the manufacturer's profit is decreasing, while the retailer's profit is increasing as retailer's portion $\theta$ increases under $P S$, which implies that it is likely that manufacturer's profit under $P S, \Pi_{m}^{P S *}$, is higher than that under $B S, \Pi_{m}^{B S *}$, when $\theta$ is relatively low. In contrast, it is likely that retailer's profit under $P S, \Pi_{r}^{P S *}$, is higher than that under $B S, \Pi_{r}^{B S *}$, when $\theta$ is relatively high. 
In Figure 3, red, blue, and black squares, respectively, represent manufacturer's best profit, retailer's best profit, and total channel's best profits (the maximum of manufacturer's profit plus retailer's profit) under PS. As we can observe in Figure 3, all the best profits are increasing as the impact of the retailer's sustainability development effort, $k_{r}$, increases. Moreover, the value of $\theta$ that makes the best total channel profit (hereafter $\theta^{P S *}$ : the $x$-coordinate of black square in Figure 3 ) increases as $k_{r}$ increases, which implies that the SC might emphasize retailer by sharing more unit profit margin so that it can encourage retailer to increase its effort level in sustainability development. As a result, retailer's additional gain (profit) from $P S$ might be increasing (i.e., $\Pi_{r}^{P S *}-\Pi_{r}^{B S *}$ increases), while manufacturer's additional gain from $P S$ might be decreasing (i.e., $\Pi_{m}^{P S *}-\Pi_{m}^{B S *}$ decreases) as $k_{r}$ increases at $\theta^{P S *}$. The result also shows that it is not guaranteed that $\Pi_{r}^{P S *}>\Pi_{r}^{B S *}$ and $\Pi_{m}^{P S *}>\Pi_{m}^{B S *}$ at $\theta^{P S *}$, which means that $\theta^{P S *}$ is not always agreed upon by both parties simultaneously (in Figure 3 , both parties in plots at $k_{r}=2$ and $k_{r}=6$ can agree, but those in plots at $k_{r}=1,3,4$, and 5 cannot agree with $\theta^{P S *}$ ).

Even though $\theta^{P S *}$ is not agreed upon by both parties, there still exists a chance that both parties might prefer $P S$ to $B S$, since there exists a range that achieves Win-Win, i.e., provides additional profits to both parties. In Figure 3, the shaded range of $\theta$ in grey represents the Win-Win range, which implies that there is a chance of consensus in a sharing mechanism decision.

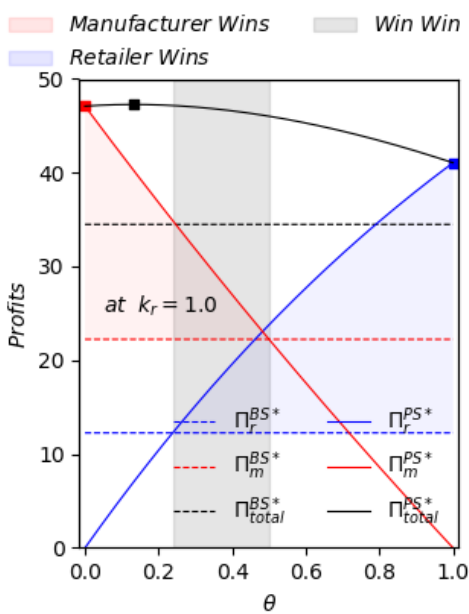

(a)

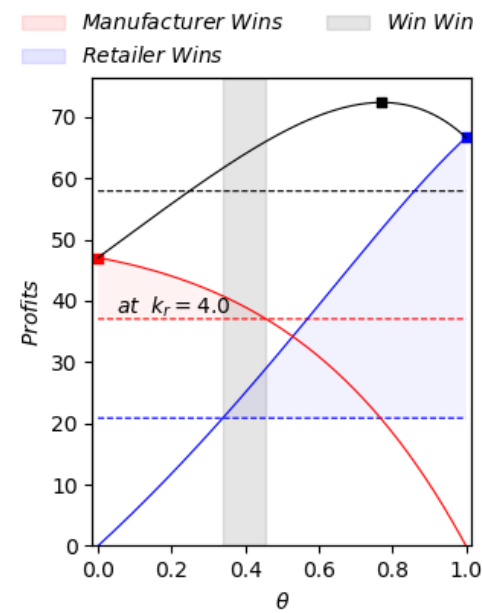

(d)

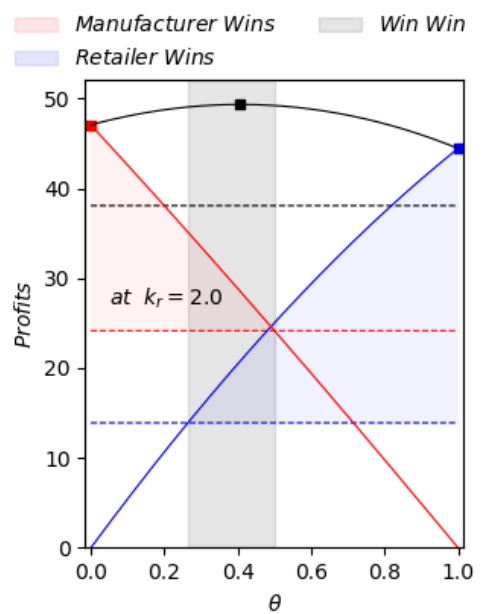

(b)

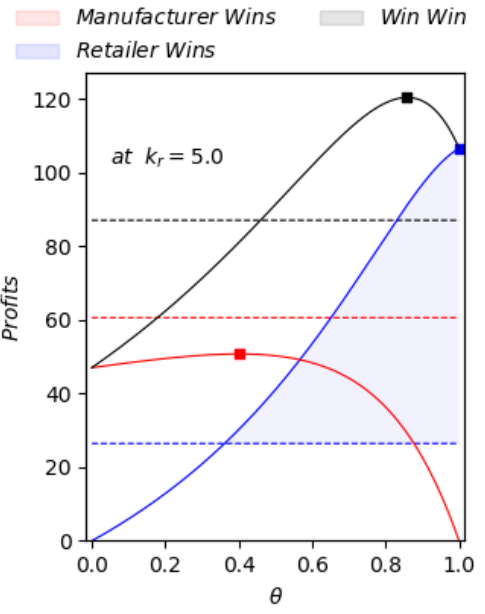

(e)

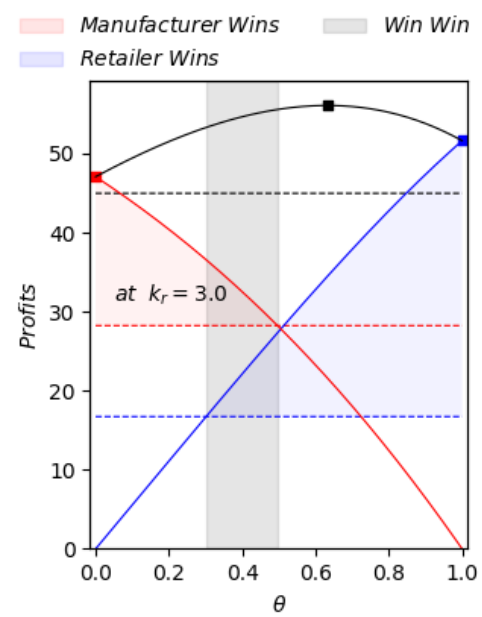

(c)

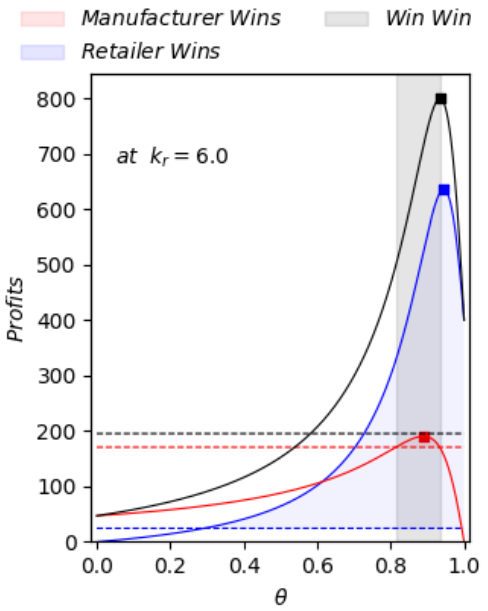

(f)

Figure 3. Baseline Sustainability (BS) model vs. Partial Sharing (PS) model over $\theta$ at different $k_{r}$, i.e., (a) at $k_{r}=1.0,(\mathbf{b})$ at $k_{r}=2.0,(\mathbf{c})$ at $k_{r}=3.0,(\mathbf{d})$ at $k_{r}=4.0,(\mathbf{e})$ at $k_{r}=5.0$, and (f) at $k_{r}=6.0$. 
As $k_{r}$ increases, the range of $\theta$ decreases. However, it increases after a certain value of $k_{r}$. Intuitively, when $\theta=0(\theta=1)$, retailer's (manufacturer's) profit in PS will be zero; thus, when $k_{r}$ is very low, i.e., $k_{r}=1$ in Figure 3, PS with very low (medium to high), $\theta$ will not be preferred by retailer (manufacturer). A similar pattern is also observed in Figure 3 at $k_{r}=2,3,4$ and 5 . In these cases, the range of Win-Win (chance of consensus) decreases. The increased $k_{r}$ leads the manufacturer to sacrifice its additional profit that can be gained under PS, because the increased $k_{r}$ can be viewed as increased bargaining power of the retailer. However, when $k_{r}$ is extremely high (i.e., at $k_{r}=6$ in Figure 3), retailer's effort level will be very high (as shown in Figure 2 in Section 3.2) compared to manufacturer's effort level. Therefore, the range of Win-Win will locate at very high $\theta$.

$P S$ will be selected only when both parties can enjoy additional profits from PS. In Figure 3, however, $P S$ does not have Win-Win range when $k_{r}=5$. Thus, now we investigate whether $F S$ can be selected under our parameter set (i.e., there exists the possibility that $F S$ can be a better mechanism for both parties). In Figure 4, we compare BS, PS, and FS simultaneously. The first, second, and third columns of Figure 4 represent manufacturer's best choice, retailer's best choice, and Win-Win choice (overlaps of first and second columns, i.e., chance of consensus in mechanism decision made by both parties) over $\theta$ and $\gamma$ at different $k_{r}$, respectively.

Red and blue points in Figure 4 represent the manufacturer's and retailer's best coordinates of $(\theta, \gamma)$ within the Win-Win range, respectively. As we can observe, the range of $\theta$ within Win-Win range under $F S$ is expanded compared to that under $P S$, which implies that $F S$ provides more chance that both parties can achieve additional profits than $P S$. When $k_{r}=1$, intuitively, the manufacturer wants to share less unit profit margin. To induce the retailer to participate in the $F S$, the manufacturer might offer less fixed cost sharing portion $\gamma$ than $\theta$, i.e., $\theta>\gamma$, reducing retailer's responsibility in JSD cost.

As $k_{r}$ increases (from $k_{r}=1$ to 5), the range of $\theta$ and $\gamma$ within Win-Win (located in FS) range is extended, which can be interpreted as the manufacturer and retailer having more options in the $(\theta, \gamma)$ coordinates. However, manufacturer's and retailer's maximum performance is more likely to be on the diagonal $(\theta=\gamma)$ line. The conflict between manufacturer's preference and retailer's preference becomes more overt, i.e., the Euclidian distance between red and blue points increases. Finally, at $k_{r}=6$, there is no chance that the two parties can make a consensus with FS. In this case, PS provides two parties with a chance of consensus in mechanism decision. Therefore, we can conclude that $F S$ can be the best sharing mechanism that provides the most additional profits to both parties, simultaneously. However, as the impact of the retailer's effort in the JSD increases, the degree of conflict between two parties increases, thus PS could be the alternative when the impact of a retailer's effort becomes very high. This implies that, in the general decision-making scenario (manufacturer moves first and then retailer follows), more flexibility in the sharing mechanism provides more chance the total channel profit is closer to first best (channel profit achieved under centralized structure). However, the increased flexibility generates more competition between the two parties, in terms of additional profit sharing. Therefore, we can conclude that, if the relationship between the impacts of sustainability efforts is inconsistent with the decision-making sequence (i.e., the impact of retailer's effort is higher than that of manufacturer's effort on consumer demand), the sharing mechanism that has less flexibility (PS) can lead to consensus rather than the one that has more flexibility (FS). 


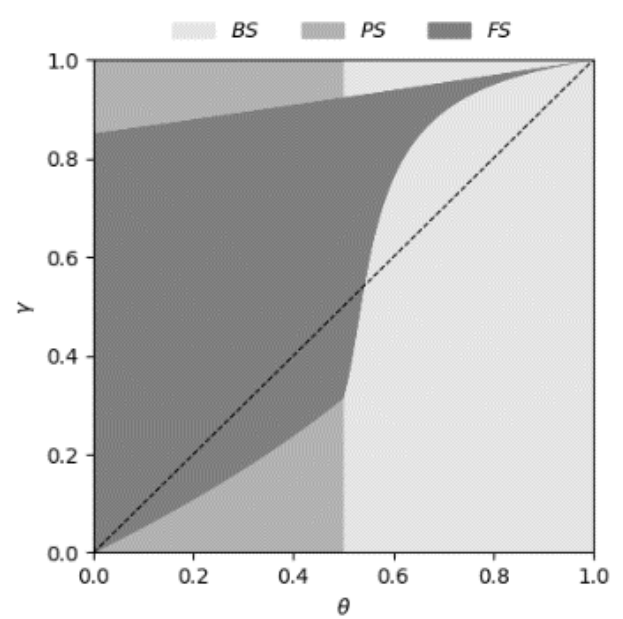

(a) Manufacturer at $k_{r}=1.0$

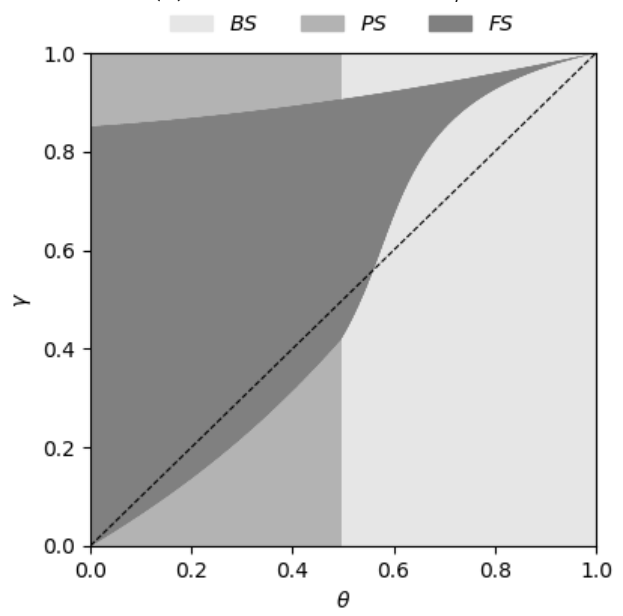

(d) Manufacturer at $k_{r}=3.0$

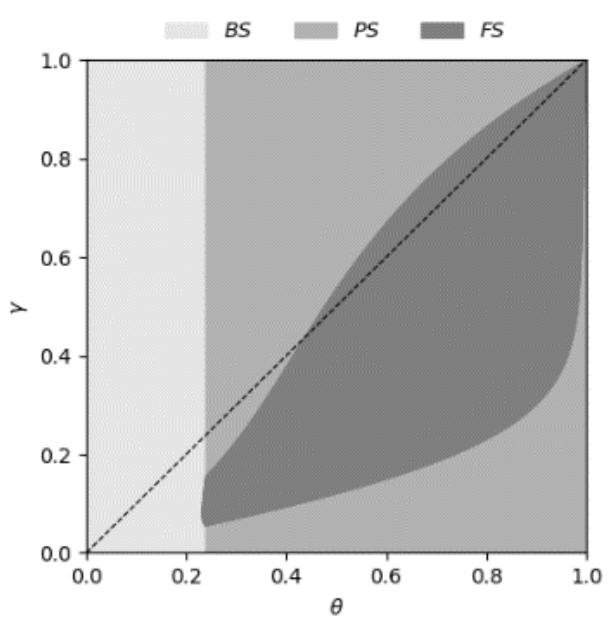

(b) Retailer at $k_{r}=1.0$

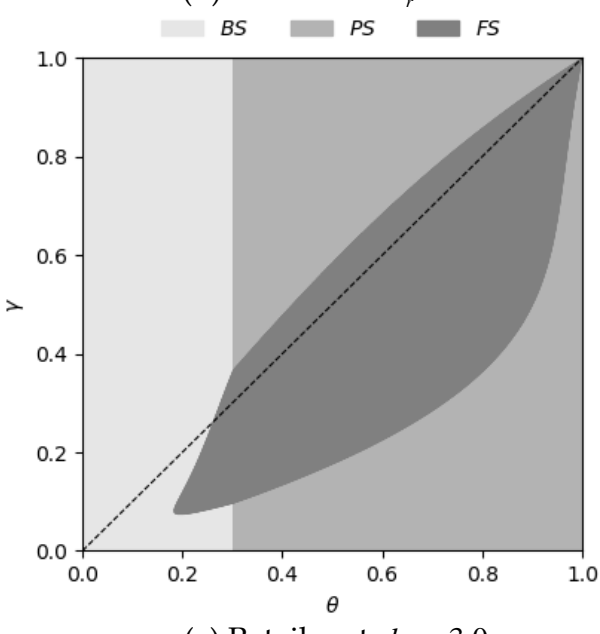

(e) Retailer at $k_{r}=3.0$

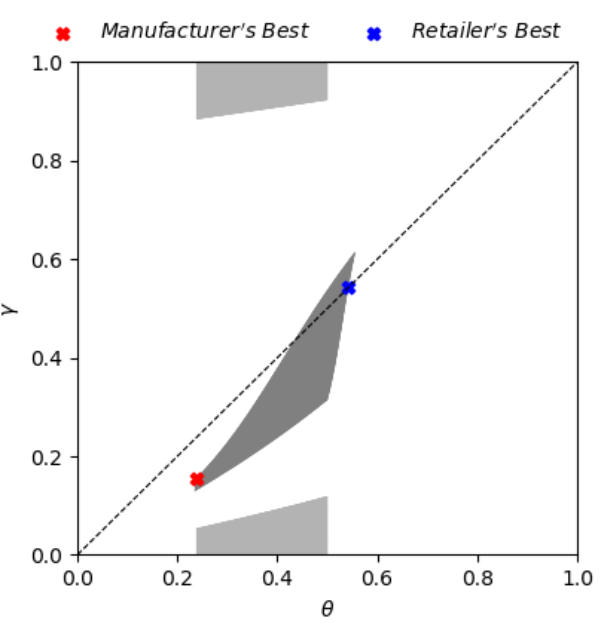

(c) Win-Win at $k_{r}=1.0$

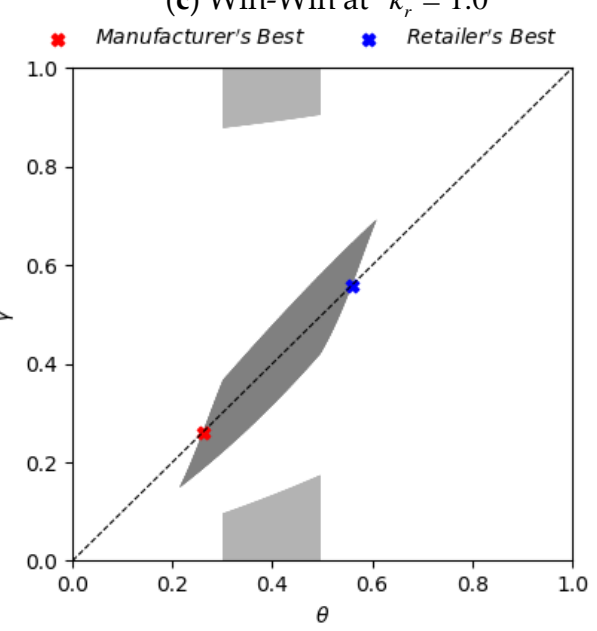

(f) Win-Win at $k_{r}=3.0$

Figure 4. Cont 


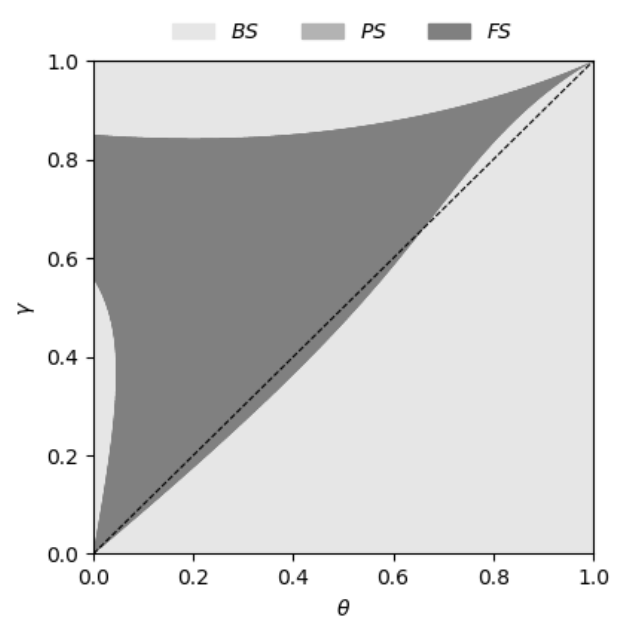

(g) Manufacturer at $k_{r}=5.0$

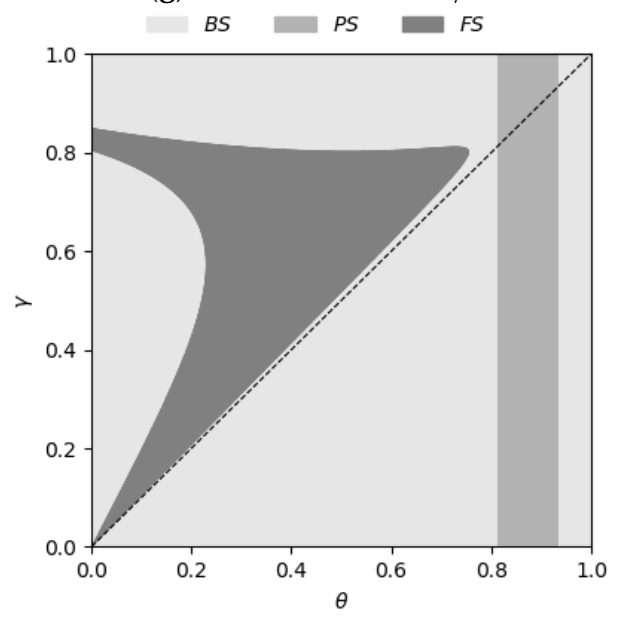

(j) Manufacturer at $k_{r}=6.0$

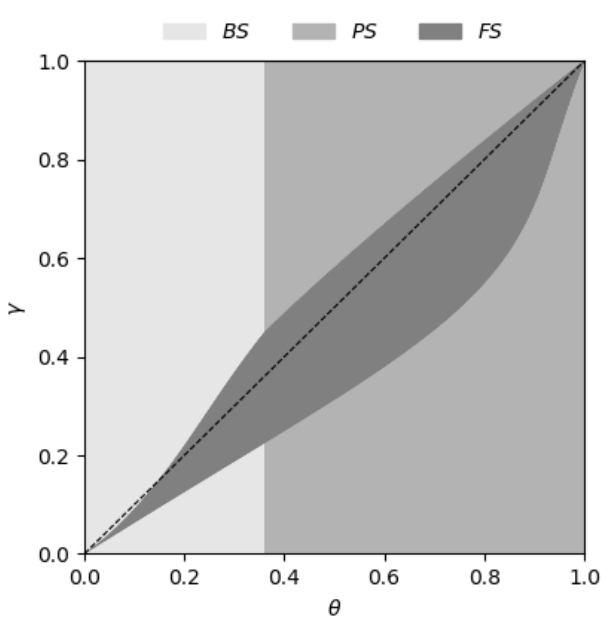

(h) Retailer at $k_{r}=5$.0

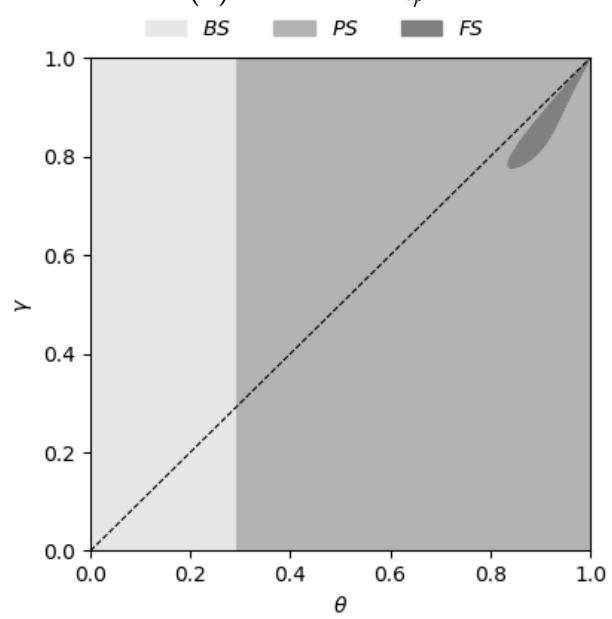

(k) Retailer at $k_{r}=6.0$

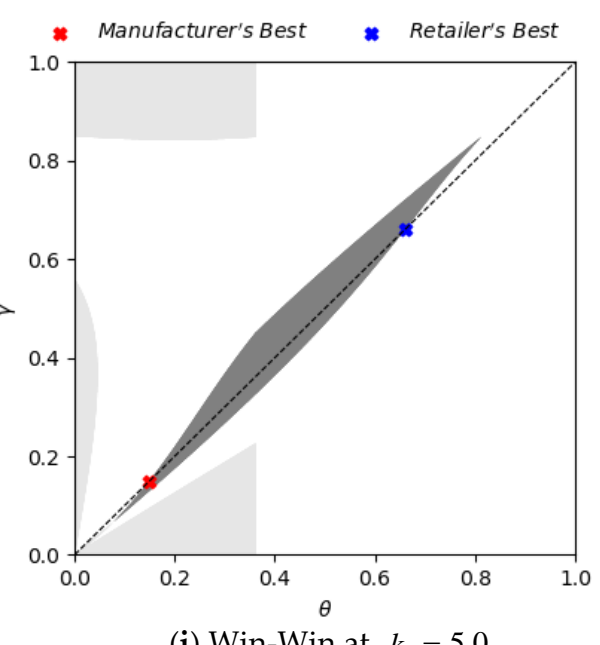

(i) Win-Win at $k_{r}=5.0$

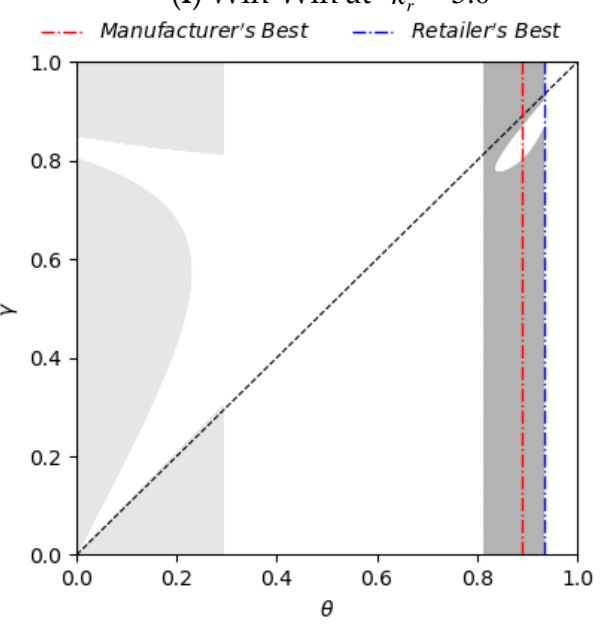

(1) Win-Win at $k_{r}=6.0$

Figure 4. Baseline Sustainability (BS) model vs. Partial Sharing (PS) model vs. Full Sharing (FS) model $\theta$ at $\alpha=100, \beta=10, k_{m}=3.0, \lambda_{r}=2.0, \lambda_{m}=3.0, c_{r}=1.0$, and $c_{m}=5.0$. 


\section{Conclusions and Implications}

The extant sustainability literature has highlighted that SC members can gain both financial and operational benefits from a SC-wide sustainability, and JSD had been viewed as an ideal approach for creating a sustainable SC. However, bounded rationality and potential opportunistic behaviors have discouraged SC members from making meaningful investments and commitments for JSD [15,16]. As a result, no guidance has been provided on how SC members could collaborate on their sustainability development efforts to achieve the intended economic performance. To bridge this gap between the theoretical benefits and the real-world application of JSD, this study proposed different contractual arrangements, based on game-theoretic approach, for both manufacturer and retailer to better engage them in JSD.

First, we investigated how the impact of SC members' sustainability development efforts on consumer demand influences their decisions in terms of pricing and JSD effort levels. Our analytical investigation found the manufacturer behaves opportunistically when the impact of a retailer's effort on consumer demand is low. When the impact of a retailer's effort on sustainability is low, in other words, the retailer increases its effort to develop sustainability, while the manufacturer decreases its effort. However, such opportunistic behavior did not occur when the impact of retailer's effort on sustainability was relatively high ( $k_{r}=5.0$ in our numerical experiment). That is, manufacturer becomes cooperative with retailer, and both retailer and manufacturer increase their efforts on sustainability development. These results show why individual sustainability efforts of manufacturer or retailer are often unsuccessful in drawing the expected sustainability performances, which call corporate sustainability practitioners' attention to their SC counterpart's opportunistic behavior in sustainability development. This reaffirms that corporate sustainability is not just one company's isolated decision but very context dependent with regard to the demand impacts of SC members' sustainability efforts. Our findings further confirm that companies occupying different positions in the SC have differential impacts on consumer demand and, thus, can behave opportunistically in JSD implementation, which reinforces the need for contractual safeguarding as a governance mechanism.

Second, the current research provides corporate sustainability practitioners with a set of contractual arrangements as governance mechanism for preventing JSD participants from opportunistic behavior. In doing so, our numerical examples showed that both manufacturer and retailer should align their revenue sharing mechanism ( $P S$ or $F S$ ) with their decision-making sequence and impacts on consumer demand. Specifically, if the manufacturer, whose impact on consumer demand is higher than that of the retailer, decides its own sustainability development effort level and wholesale price first and the retailer follows, both parties are more likely to choose a flexible sharing mechanism (i.e., FS). In this case, channel profit is close to the one under a centralized SC. On the other hand, if the impacts of JSD efforts do not match with the decision-making sequence of manufacturer and retailer (i.e., manufacturer makes decisions first or later while its impact on consumer demand is lower or higher than that of retailer), the two parties might choose a less flexible sharing mechanism (i.e., $P S$ ) whose channel profit might fall far below what could be obtained under centralized SC. These results prove that a revenue sharing mechanism can serve as an effective governance mechanism against opportunism and enable the manufacturer and retailer to devise and implement a mutually beneficial JSD program.

Finally, we provide detailed guidelines for the mutually beneficial contract (i.e., preferred derivative of revenue sharing mechanism) that can encourage both SC members' JSD efforts. A series of numerical experiments were carried out to compare the effectiveness of three different contractual mechanisms SC practitioners may consider in pursuit of JSD: no sharing (BS), unit profit margin sharing (partial sharing; $P S$ ), and total profit and fixed cost sharing (full sharing; FS). We first confirmed that both the manufacturer and the retailer could gain more profits under FS than under PS mechanism. To encourage the retailer to participate in the $F S$, the manufacturer could offer a share of retailer's JSD cost. The agreement on JSD between manufacturer and retailer is more difficult to reach when the impact of retailer's effort on consumer demand increases. PS can be an effective alternative in such 
situations. In a general decision-making sequence, a flexible sharing mechanism provides a better chance of achieving the total channel profit closer to the one under centralized SC (first best). As the flexibility increases, however, manufacturer and retailer can compete against each other in sharing additional profits. If the relationship between the impacts of sustainability efforts is not consistent with the decision-making sequence, a less flexible contractual arrangement (such as PS which is an inferior mechanism in terms of channel profit perspective) would be better for leading to consensus than more flexible ones (such as FS which is superior mechanism). We expect retailers and manufacturers that are or interested in developing or managing sustainability practices across their value chains could adopt our framework and check whether the right contractual arrangements are in place.

There are several research limitations to this study, which suggest promising avenues for future research. For instance, we consider additive form in Equation (6) but the different demand-price functions, such as a multiplicative form or an exponential form, may yield additional results and implications. Moreover, we did not consider an SC coordination issue in this study. In addition, we only considered one manufacturer and one retailer setting. Investigating JSD issues with multiple manufacturers and retailers from an SC coordination perspective would provide more practical implications (including not only vertical competition but also horizontal competitions in a dynamic SC). Finally, more sophisticated contractual arrangements can also be considered in JSD. For example, price discount contract and fixed quota policy might provide more specific and realistic managerial implications. Despite these limitations, this study makes significant contributions to the theory and practice of sustainable SC by highlighting the potential of a revenue sharing contract as a governance mechanism and providing detailed action plans to ensure JSD commitments from manufacturer and retailer.

Author Contributions: Y.X. and J.Y. developed the original idea and mathematical models and analyzed the models for the study. M.K.K. was responsible for writing of the manuscript. C.S. reviewed the manuscript.

Conflicts of Interest: The authors declare no conflict of interest.

\section{Appendix A}

Proof for Proposition 1. First, we solve the baseline problems under decentralized SC. We can revise Equations (1) and (2) using $\theta\left[p-\left(c_{r}+c_{m}\right)\right]=p-w-c_{r}$ and $(1-\theta)\left[p-\left(c_{r}+c_{m}\right)\right]=w-c_{m}$ as follows:

$$
\begin{gathered}
\Pi_{r}^{B}=\theta\left[p-\left(c_{r}+c_{m}\right)\right](\alpha-\beta p) \\
\Pi_{m}^{B}=(1-\theta)\left[p-\left(c_{r}+c_{m}\right)\right](\alpha-\beta p)
\end{gathered}
$$

It can be shown that $\Pi_{r}^{B}$ and $\Pi_{m}^{B}$ are concave in $p$ and $w$, respectively. Thus, equilibrium retail price and wholesale price are given by

$$
p^{B *}=\frac{\alpha}{2 \beta}+\frac{c_{r}+c_{m}}{2} \text { and } w^{B *}=(1-\theta)\left[\frac{\alpha}{2 \beta}-\frac{c_{r}+c_{m}}{2}\right]+c_{m} \text {, respectively }
$$

Now, we solve Equation (3) for centralized SC. The total SC profit function can be revised under the assumption of unit profit margin sharing as follows:

$$
\Pi_{\text {total }}^{B}=\left[p-\left(c_{r}+c_{m}\right)\right](\alpha-\beta p)
$$

Again, it is easily shown that $\Pi_{\text {total }}^{B}$ is concave in $p$ and optimal retail price is given by

$$
p_{\text {total }}^{B *}=\frac{\alpha}{2 \beta}+\frac{c_{r}+c_{m}}{2}=p^{B *}
$$

Therefore, there is no double marginalization under unit profit margin sharing. If we solve $\Pi_{r}^{B}$ for $p$ under decentralized SC, without the unit profit margin sharing structure, then $p^{B *}=\frac{\alpha}{2 \beta}+\frac{w+c_{r}}{2}$. 
We claim that $p^{B *}=\frac{\alpha}{2 \beta}+\frac{w+c_{r}}{2}>\frac{\alpha}{2 \beta}+\frac{c_{m}+c_{r}}{2}=p_{\text {total }}^{B *} \Leftrightarrow w-c_{m}>0$, which is always true, since the manufacturer's unit profit margin should be non-negative by definition. This implies that we can expect that double marginalization will arise without the unit profit margin sharing structure. Therefore, the unit profit sharing condition, $p-w-c_{r}=\Theta\left(w-c_{m}\right)$, can remove the double marginalization effect.

Proof for Proposition 2. Retailer's and manufacturer's problems are given by:

$$
\begin{gathered}
\max _{p \geq 0, \eta_{r} \geq 0}\left\{\Pi_{r}^{B S}=\left(p-w-c_{r}\right)\left(\alpha-\beta p+k_{m} \eta_{m}+k_{r} \eta_{r}\right)-\frac{\lambda_{r} \eta_{r}{ }^{2}}{2}\right\} \\
\max _{w \geq 0, \eta_{m} \geq 0}\left\{\Pi_{m}^{B S}=\left(w-c_{m}\right)\left(\alpha-\beta p+k_{m} \eta_{m}+k_{r} \eta_{r}\right)-\frac{\lambda_{m} \eta_{m}{ }^{2}}{2}\right\}
\end{gathered}
$$

As we assumed the manufacturer moves first and the retailer follows, i.e., the manufacturer decides wholesale price and sustainability development effort first and the retailer will then decide retail price and its sustainability development effort. Thus, we solve the problems by using backward induction, i.e., solve retailer's problem first and then solve manufacturer's problem.

It can be easily shown that $\Pi_{r}^{B S}$ is concave in $p$ and $\eta_{r}$, since $\frac{\partial \Pi_{r}^{B S}}{\partial \eta_{r}}=k_{r}\left(p-w-c_{r}\right)-\lambda_{r} \eta_{r}$, $\frac{\partial^{2} \Pi_{r}^{B S}}{\partial \eta_{r}{ }^{2}}=-\lambda_{r}<0, \frac{\partial \Pi_{r}^{B S}}{\partial p}=\alpha-\left(2 p-w-c_{r}\right) \beta+k_{r} \eta_{r}+k_{m} \eta_{m}$ and $\frac{\partial^{2} \Pi_{r}^{B S}}{\partial p^{2}}=-2 \beta<0$, F.O.C. gives

$$
\begin{gathered}
\eta_{r}^{B S *}=\frac{k_{r}\left(p-w-c_{r}\right)}{\lambda_{r}} \\
p^{B S *}=\frac{\alpha+\left(w+c_{r}\right) \beta+k_{m} \eta_{m}+k_{r} \eta_{r}}{2 \beta}
\end{gathered}
$$

Note that $\frac{\partial^{2} \Pi_{r}^{B S}}{\partial \eta_{r} \partial p}=\frac{\partial^{2} \Pi_{r}^{B S}}{\partial p \partial \eta_{r}}=k_{r}$. Thus, Equations (A8) and (A9) holds iff $2 \beta \lambda_{r}-k_{r}^{2}>0$, i.e., positive definite. Plugging Equations (A8) and (A9) into Equation (A7) gives

$$
\Pi_{m}^{B S}=\frac{\left(w-c_{m}\right)\left(p-w-c_{r}\right) k_{r}^{2}+\left[\left(w-c_{m}\right)\left[\alpha-\left(w+c_{r}\right) \beta+k_{m} \eta_{m}\right]-\lambda_{m} \eta_{m}{ }^{2}\right] \lambda_{r}}{2 \lambda_{r}}
$$

Thus, $\frac{\partial \Pi_{m}^{B S}}{\partial \eta_{m}}=\frac{\left(w-c_{m}\right) k_{m}-2 \lambda_{m} \eta_{m}}{2}$ and $\frac{\partial^{2} \Pi_{m}^{B S}}{\partial \eta_{m}^{2}}=-\lambda_{m}<0$ so that F.O.C. gives

$$
\eta_{m}^{B S *}=\frac{\left(w-c_{m}\right) k_{m}}{2 \lambda_{m}}
$$

$\frac{\partial \Pi_{m}^{B S}}{\partial w}=\frac{\alpha-\left(2 w-c_{m}+c_{r}\right) \beta+k_{m} \eta_{m}}{2}+\frac{\left[p-\left(2 w-c_{m}+c_{r}\right)\right] k_{r}^{2}}{2 \lambda_{r}}$ and $\frac{\partial^{2} \Pi_{m}^{B S}}{\partial w^{2}}=-\beta-\frac{k_{r}{ }^{2}}{\lambda_{r}}<0$ so that F.O.C. gives

$$
w^{B S *}=\frac{\left(p+c_{m}-c_{r}\right) k_{r}^{2}+\left[\alpha+\left(c_{m}-c_{r}\right) \beta+k_{m} \eta_{m}\right] \lambda_{r}}{2\left(\beta \lambda_{r}+k_{r}^{2}\right)}
$$

Note that $\frac{\partial^{2} \Pi_{m}^{B S}}{\partial \eta_{m} \partial w}=\frac{\partial^{2} \Pi_{m}^{B S}}{\partial w \partial \eta_{m}}=\frac{k_{m}}{2}$. Thus, Equations (A11) and (A12) hold iff $\beta \lambda_{m}+\frac{\lambda_{m} k_{r}{ }^{2}}{\lambda_{r}}-\frac{k_{m}{ }^{2}}{4}>0$, i.e., negative definite. Solving Equations (A8), (A9), (A11), and (A12) simultaneously, we can derive the following.

$$
\begin{gathered}
\eta_{m}^{B S *}=k_{m} \lambda_{r}{ }^{2} \beta\left[\alpha-\beta\left(c_{m}+c_{r}\right)\right] \Psi^{B S} \\
w^{B S *}=\left[\beta c_{m} k_{r}{ }^{2} \lambda_{m} \lambda_{r}-\beta \lambda_{r}{ }^{2}\left[c_{m} k_{m}{ }^{2}-2 \beta\left(c_{m}-c_{r}\right) \lambda_{m}-2 \alpha \lambda_{m}\right]-c_{m} k_{r}{ }^{4} \lambda_{m}\right] \Psi^{B S} \\
\eta_{r}^{B S *}=k_{r} \lambda_{m}\left(k_{r}{ }^{2}+\beta \lambda_{r}\right)\left[\alpha-\beta\left(c_{m}+c_{r}\right)\right] \Psi^{B S} \\
p^{B S *}=\left[\alpha k_{r}{ }^{2} \lambda_{m} \lambda_{r}-\beta \lambda_{r}{ }^{2}\left[\left(c_{m}+c_{r}\right) k_{m}{ }^{2}-\beta\left(c_{m}+c_{r}\right) \lambda_{m}-3 \alpha \lambda_{m}\right]-\left(c_{m}+c_{r}\right) k_{r}{ }^{4} \lambda_{m}\right] \Psi^{B S}
\end{gathered}
$$


where $\Psi^{B S}=\frac{1}{\left(\beta \lambda_{r}-k_{r}{ }^{2}\right) k_{r}{ }^{2} \lambda_{m}+\beta\left(4 \beta \lambda_{m}-k_{m}^{2}\right) \lambda_{r}{ }^{2}}$.

Proof for Proposition 3. Retailer's and manufacturer's problems are given by:

$$
\begin{gathered}
\max _{p \geq 0, \eta_{r} \geq 0}\left\{\Pi_{r}^{P S}=\theta\left[p-\left(c_{r}+c_{m}\right)\right]\left[\alpha-\beta p+k_{m} \eta_{m}+k_{r} \eta_{r}\right]-\frac{\lambda_{r} \eta_{r}{ }^{2}}{2}\right\} \\
\max _{w \geq 0, \eta_{m} \geq 0}\left\{\Pi_{m}^{P S}=(1-\theta)\left[p-\left(c_{r}+c_{m}\right)\right]\left[\alpha-\beta p+k_{m} \eta_{m}+k_{r} \eta_{r}\right]-\frac{\lambda_{m} \eta_{m}{ }^{2}}{2}\right\}
\end{gathered}
$$

As we assumed, the manufacturer decides wholesale price and level of sustainability development effort first and the retailer will then decide retail price and its level of sustainability development effort. However, retail price is a function of wholesale price and vice versa under a unit profit margin sharing structure. Thus, the decision on retail price by the retailer will compute the wholesale price automatically in a backward induction process.

It can easily be shown that $\Pi_{r}^{P S}$ is concave in $p$ and $\eta_{r}$, while $\Pi_{m}^{P S}$ is concave in $w$ and $\eta_{m}$, since

$$
\begin{gathered}
\frac{\partial \Pi_{r}^{P S}}{\partial \eta_{r}}=k_{r} \theta\left[p-\left(c_{r}+c_{m}\right)\right]-\lambda_{r} \eta_{r} \text { and } \frac{\partial^{2} \Pi_{r}^{P S}}{\partial \eta_{r}^{2}}=-\lambda_{r}<0 \text { so that F.O.C. gives } \\
\eta_{r}^{P S *}=\frac{k_{r} \theta\left[p-\left(c_{r}+c_{m}\right)\right]}{\lambda_{r}} \\
\frac{\partial \Pi_{r}^{P S}}{\partial p}=\theta\left[\alpha-\left[2 p-\left(c_{r}+c_{m}\right)\right] \beta+k_{r} \eta_{r}+k_{m} \eta_{m}\right] \text { and } \frac{\partial^{2} \Pi_{r}^{P S}}{\partial p^{2}}=-2 \beta \theta<0 \text { so that F.O.C. gives } \\
p^{P S *}=\frac{\alpha+\left(c_{r}+c_{m}\right) \beta+k_{m} \eta_{m}+k_{r} \eta_{r}}{2 \beta}
\end{gathered}
$$

Thus, we solve $\eta_{r}^{P S *}$ and $p^{P S *}$ simultaneously and update as follows:

$$
\eta_{r}^{P S *}=\frac{k_{r} \theta\left[\alpha-\left(c_{r}+c_{m}\right) \beta+k_{m} \eta_{m}\right]}{2 \lambda_{r} \beta-k_{r}^{2} \theta} \text { and } p^{P S *}=\frac{\lambda_{r}\left[\alpha-\left(c_{r}+c_{m}\right) \beta+k_{m} \eta_{m}\right]}{2 \lambda_{r} \beta-k_{r}^{2} \theta}+c_{r}+c_{m}
$$

Note that $\frac{\partial^{2} \Pi_{r}^{D}}{\partial \eta_{r} \partial p}=\frac{\partial^{2} \Pi_{r}^{D}}{\partial p \partial \eta_{r}}=k_{r} \theta$. Thus, Equation (A18) holds iff $\left(2 \beta \lambda_{r}-k_{r}{ }^{2} \theta\right) \theta>0$, i.e., negative definite. Plugging $\eta_{r}^{P S *}$ and $p^{P S *}$ from Equations (A16) and (A17) into $\eta_{r}$ and $p$ of Equation (A15) gives

$$
\Pi_{m}^{P S}=\frac{\lambda_{r}^{2} \beta\left[\alpha-\left(c_{r}+c_{m}\right) \beta+k_{m} \eta_{m}\right]^{2}}{\left(k_{r}^{2} \theta-2 \lambda_{r} \beta\right)^{2}}(1-\theta)-\frac{\lambda_{m} \eta_{m}^{2}}{2}
$$

$\frac{\partial \Pi_{m}^{P S}}{\partial \eta_{m}}=\frac{2 k_{m} \lambda_{r}{ }^{2} \beta(1-\theta)\left[\alpha-\left(c_{r}+c_{m}\right) \beta+k_{m} \eta_{m}\right]}{\left(k_{r}^{2} \theta-2 \lambda_{r} \beta\right)^{2}}-\lambda_{m} \eta_{m}$ and $\frac{\partial^{2} \Pi_{m}^{P S}}{\partial \eta_{m}{ }^{2}}=-\lambda_{m}+\frac{2 \beta k_{m}{ }^{2} \lambda_{r}{ }^{2}(1-\theta)}{\left(k_{r}{ }^{2} \theta-2 \lambda_{r} \beta\right)^{2}}<0$ (note that if $\frac{\partial^{2} \Pi_{m}^{P S}}{\partial \eta_{m^{2}}}>0, \eta_{m}^{P S *}=0$ because the cost of sustainability development is exponentially increasing) so that F.O.C. gives

$$
\eta_{m}^{P S *}=\frac{2 k_{m} \lambda_{r}^{2} \beta\left[\alpha-\left(c_{r}+c_{m}\right) \beta\right](1-\theta)}{\lambda_{m}\left(k_{r}^{2} \theta-2 \beta \lambda_{r}\right)^{2}-2 \beta k_{m}^{2} \lambda_{r}^{2}(1-\theta)}
$$

Plugging Equation (A20) into Equation (A18) updates $\eta_{r}^{P S *}$ and $p^{P S *}$ as follows:

$$
\begin{gathered}
\eta_{r}^{P S *}=\frac{k_{r} \lambda_{m} \theta\left[\alpha-\left(c_{r}+c_{m}\right) \beta\right]\left(2 \beta \lambda_{r}-k_{r}^{2} \theta\right)}{\lambda_{m}\left(k_{r}^{2} \theta-2 \beta \lambda_{r}\right)^{2}-2 \beta k_{m}^{2} \lambda_{r}^{2}(1-\theta)} \text { and } \\
p^{P S *}=\frac{\lambda_{r} \lambda_{m}\left[\alpha-\left(c_{r}+c_{m}\right) \beta\right]\left(2 \beta \lambda_{r}-k_{r}^{2} \theta\right)}{\lambda_{m}\left(k_{r}^{2} \theta-2 \beta \lambda_{r}\right)^{2}-2 \beta k_{m}^{2} \lambda_{r}{ }^{2}(1-\theta)}+c_{r}+c_{m}
\end{gathered}
$$


Finally, plugging $p^{P S *}$ into the unit profit margin sharing structure we define, i.e., $w=$ $(1-\theta)\left[p-\left(c_{r}+c_{m}\right)\right]+c_{m}$, gives

$$
w^{P S *}=\frac{\lambda_{r} \lambda_{m}\left[\alpha-\left(c_{r}+c_{m}\right) \beta\right]\left(2 \beta \lambda_{r}-k_{r}^{2} \theta\right)}{\lambda_{m}\left(k_{r}^{2} \theta-2 \beta \lambda_{r}\right)^{2}-2 \beta k_{m}^{2} \lambda_{r}^{2}(1-\theta)}(1-\theta)+c_{m}
$$

We can simplify the equilibriums derived above as follows:

$$
\begin{gathered}
\eta_{m}^{P S *}=2 k_{m} \lambda_{r}^{2} \beta(1-\theta) \Psi^{P S} \\
w^{P S *}=\lambda_{r} \lambda_{m}\left(2 \beta \lambda_{r}-k_{r}^{2} \theta\right)(1-\theta) \Psi^{P S}+c_{m} \\
\eta_{r}^{P S *}=k_{r} \lambda_{m} \theta\left(2 \beta \lambda_{r}-k_{r}^{2} \theta\right) \Psi^{P S} \\
p^{P S *}=\lambda_{r} \lambda_{m}\left(2 \beta \lambda_{r}-k_{r}^{2} \theta\right) \Psi^{P S}+c_{r}+c_{m},
\end{gathered}
$$

where $\Psi^{P S}=\frac{\alpha-\left(c_{r}+c_{m}\right) \beta}{\lambda_{m}\left(k_{r}^{2} \theta-2 \beta \lambda_{r}\right)^{2}-2 \beta k_{m}^{2} \lambda_{r}^{2}(1-\theta)}$.

Proof for Proposition 6. Centralized SC problem is given by:

$$
\max _{p \geq 0, \eta_{r} \geq 0, \eta_{m} \geq 0}\left\{\Pi_{\text {total }}^{C P S}=\left[p-\left(c_{r}+c_{m}\right)\right]\left[\alpha-\beta p+k_{m} \eta_{m}+k_{r} \eta_{r}\right]-\frac{\lambda_{r} \eta_{r}^{2}}{2}-\frac{\lambda_{m} \eta_{m}^{2}}{2}\right\}
$$

It can easily be shown that $\Pi_{\text {total }}^{C P S}$ is concave in $p, \eta_{r}$, and $\eta_{m}$, since

$$
\eta_{r}^{C P S *}=\frac{k_{r}\left[p-\left(c_{r}+c_{m}\right)\right]}{\lambda_{r}}
$$

$\frac{\partial \Pi_{\text {total }}^{\text {CPS }}}{\partial \eta_{m}}=k_{m}\left[p-\left(c_{r}+c_{m}\right)\right]-\lambda_{m} \eta_{m}$ and $\frac{\partial^{2} \Pi_{\text {total }}^{C P S}}{\partial \eta_{m}^{2}}=-\lambda_{m}<0$ so that F.O.C. gives

$$
\eta_{m}^{C P S *}=\frac{k_{m}\left[p-\left(c_{r}+c_{m}\right)\right]}{\lambda_{m}}
$$

$\frac{\partial \Pi_{\text {total }}^{C P S}}{\partial p}=\alpha-\left[2 p-\left(c_{r}+c_{m}\right)\right] \beta+k_{r} \eta_{r}+k_{m} \eta_{m}$ and $\frac{\partial^{2} \Pi_{\text {total }}^{C P S}}{\partial p^{2}}=-2 \beta<0$ so that F.O.C. gives

$$
p^{C P S *}=\frac{\alpha+\left(c_{r}+c_{m}\right) \beta+k_{m} \eta_{m}+k_{r} \eta_{r}}{2 \beta}
$$

Thus, we solve $\eta_{r}^{C P S *}, \eta_{m}^{C P S *}$ and $p^{C P S *}$ simultaneously and update as follows:

$$
\begin{gathered}
\eta_{r}^{C P S *}=\frac{k_{r} \lambda_{m}\left[\alpha-\left(c_{r}+c_{m}\right) \beta\right]}{\lambda_{m}\left(2 \beta \lambda_{r}-k_{r}^{2}\right)-k_{m}^{2} \lambda_{r}}, \eta_{m}^{C P S *}=\frac{k_{m} \lambda_{r}\left[\alpha-\left(c_{r}+c_{m}\right) \beta\right]}{\lambda_{m}\left(2 \beta \lambda_{r}-k_{r}^{2}\right)-k_{m}{ }^{2} \lambda_{r}} \text { and } \\
p^{C P S *}=\frac{\lambda_{r} \lambda_{m}\left[\alpha-\left(c_{r}+c_{m}\right) \beta\right]}{\lambda_{m}\left(2 \beta \lambda_{r}-k_{r}^{2}\right)-k_{m}^{2} \lambda_{r}}+c_{r}+c_{m}
\end{gathered}
$$

Therefore, by definition

$$
w^{C P S *}=(1-\theta)\left[p-\left(c_{r}+c_{m}\right)\right]+c_{m}=(1-\theta)\left[\frac{\lambda_{r} \lambda_{m}\left[\alpha-\left(c_{r}+c_{m}\right) \beta\right]}{\lambda_{m}\left(2 \beta \lambda_{r}-k_{r}^{2}\right)-k_{m}^{2} \lambda_{r}}\right]+c_{m}
$$


By simple algebra, we can simplify Equations (A28) and (A29) as follows:

$$
\begin{gathered}
\eta_{m}^{C P S *}=k_{m} \lambda_{r} \Psi \text { CPS } \\
w^{C P S *}=\lambda_{r} \lambda_{m}(1-\theta) \Psi C P S+c_{m} \\
\eta_{r}^{C P S *}=k_{r} \lambda_{m} \Psi \text { CPS } \\
p^{C P S *}=\lambda_{r} \lambda_{m} \Psi C P S+c_{r}+c_{m},
\end{gathered}
$$

where $\Psi^{C P S}=\frac{\alpha-\left(c_{r}+c_{m}\right) \beta}{\lambda_{m}\left(2 \beta \lambda_{r}-k_{r}^{2}\right)-k_{m}{ }^{2} \lambda_{r}}$.

Proof for Proposition 8. Retailer's and manufacturer's problems are given by:

$$
\begin{gathered}
\max _{p \geq 0, \eta_{r} \geq 0}\left\{\Pi_{r}^{F S}=\theta\left[p-\left(c_{r}+c_{m}\right)\right]\left[\alpha-\beta p+k_{m} \eta_{m}+k_{r} \eta_{r}\right]-\gamma\left(\frac{\lambda_{r} \eta_{r}^{2}}{2}+\frac{\lambda_{m} \eta_{m}{ }^{2}}{2}\right)\right\} \\
\max _{w \geq 0, \eta_{m} \geq 0}\left\{\Pi_{m}^{F S}=(1-\theta)\left[p-\left(c_{r}+c_{m}\right)\right]\left[\alpha-\beta p+k_{m} \eta_{m}+k_{r} \eta_{r}\right]-(1-\gamma)\left(\frac{\lambda_{r} \eta_{r}{ }^{2}}{2}+\frac{\lambda_{m} \eta_{m}^{2}}{2}\right)\right\}
\end{gathered}
$$

It can easily be shown that $\Pi_{r}^{F S}$ is concave in $p$ and $\eta_{r}$, since

$$
\begin{gathered}
\frac{\partial \Pi_{r}^{F S}}{\partial \eta_{r}}=k_{r} \theta\left[p-\left(c_{r}+c_{m}\right)\right]-\lambda_{r} \eta_{r} \gamma \text { and } \frac{\partial^{2} \Pi_{r}^{F S}}{\partial \eta_{r}^{2}}=-\lambda_{r} \gamma<0 \text { so that F.O.C. gives } \\
\eta_{r}^{F S *}=\frac{k_{r} \theta\left[p-\left(c_{r}+c_{m}\right)\right]}{\gamma \lambda_{r}} \\
\frac{\partial \Pi_{r}^{F S}}{\partial p}=\theta\left[\alpha-\left[2 p-\left(c_{r}+c_{m}\right)\right] \beta+k_{r} \eta_{r}+k_{m} \eta_{m}\right] \text { and } \frac{\partial^{2} \Pi_{r}^{F S}}{\partial p^{2}}=-2 \beta \theta<0 \text { so that F.O.C. gives } \\
p^{F S *}=\frac{\alpha+\left(c_{r}+c_{m}\right) \beta+k_{m} \eta_{m}+k_{r} \eta_{r}}{2 \beta}
\end{gathered}
$$

Thus, we solve $\eta_{r}^{F S *}$ and $p^{F S *}$ simultaneously and update as follows:

$$
\eta_{r}^{F S *}=\frac{\theta k_{r}\left[\alpha-\left(c_{r}+c_{m}\right) \beta+k_{m} \eta_{m}\right]}{2 \beta \gamma \lambda_{r}-k_{r}^{2} \theta} \text { and } p^{F S *}=\frac{\gamma \lambda_{r}\left[\alpha+\beta\left(c_{m}+c_{r}\right)+k_{m} \eta_{m}\right]-k_{r}^{2} \theta\left(c_{m}+c_{r}\right)}{2 \beta \gamma \lambda_{r}-k_{r}^{2} \theta}
$$

Note that $\frac{\partial^{2} \Pi_{r}^{F S}}{\partial \eta_{r} \partial p}=\frac{\partial^{2} \Pi_{r}^{F S}}{\partial p \partial \eta_{r}}=k_{r} \theta$. Thus, the results derived in Equations (A33) and (A34) holds iff $\left(2 \beta \lambda_{r} \gamma-k_{r}^{2} \theta\right) \theta>0$, i.e., positive definite. Similar to the other equilibrium derivations, plugging Equation (A35) into Equation (A42) and solving its F.O.C for $\eta_{m}$ gives $\eta_{m}^{F S *}$. Simultaneously solving $\eta_{r}^{F S *}, \eta_{m}^{F S *}$, and $p^{F S *}$ gives

$$
\begin{gathered}
\eta_{r}^{F D *}=\frac{2 \beta(1-\gamma) \gamma \theta\left[\alpha-\beta\left(c_{m}+c_{r}\right)\right] k_{r} \lambda_{m}}{2 \beta(1-\gamma) \gamma \lambda_{m}\left(2 \beta \gamma \lambda_{r}-\theta k_{r}^{2}\right)-k_{m}^{2}\left[2 \beta \gamma^{2}(1-\theta) \lambda_{r}+(\gamma-\theta) \theta k_{r}^{2}\right]}, \\
p^{F D *}=\frac{\theta\left(c_{m}+c_{r}\right) k_{r}^{2}\left[(\theta-\gamma) k_{m}^{2}-2 \beta(1-\gamma) \gamma \lambda_{m}\right]-2 \beta \lambda_{r} \gamma^{2}\left[(1-\theta)\left(c_{m}+c_{r}\right) k_{m}^{2}-(1-\gamma)\left[\alpha+\beta\left(c_{m}+c_{r}\right)\right] \lambda_{m}\right]}{2 \beta(1-\gamma) \gamma \lambda_{m}\left(2 \beta \gamma \lambda_{r}-\theta k_{r}^{2}\right)-k_{m}^{2}\left[2 \beta \gamma^{2}(1-\theta) \lambda_{r}+(\gamma-\theta) \theta k_{r}^{2}\right]}, \text { and } \\
\eta_{m}^{F D *}=\frac{\left[2 \beta \gamma^{2}(1-\theta) \lambda_{r}+(\gamma-\theta) \theta k_{r}^{2}\right]\left[\alpha-\beta\left(c_{m}+c_{r}\right)\right] k_{m}}{2 \beta(1-\gamma) \gamma \lambda_{m}\left(2 \beta \gamma \lambda_{r}-\theta k_{r}^{2}\right)-k_{m}^{2}\left[2 \beta \gamma^{2}(1-\theta) \lambda_{r}+(\gamma-\theta) \theta k_{r}^{2}\right]}
\end{gathered}
$$

Equation (A36) can be simplified

$$
\begin{gathered}
\eta_{r}^{F S *}=2 \beta(1-\gamma) \gamma \theta k_{r} \lambda_{m} \Psi F S, \\
p^{F S *}=\frac{\theta\left(c_{m}+c_{r}\right) k_{r}{ }^{2}\left[(\theta-\gamma) k_{m}{ }^{2}-2 \beta(1-\gamma) \gamma \lambda_{m}\right]-2 \beta \lambda_{r} \gamma^{2}\left[(1-\theta)\left(c_{m}+c_{r}\right) k_{m}{ }^{2}-(1-\gamma)\left[\alpha+\beta\left(c_{m}+c_{r}\right)\right] \lambda_{m}\right]}{\alpha-\beta\left(c_{m}+c_{r}\right)} \Psi F S, \text { and } \\
\eta_{m}^{F S *}=\left[2 \beta \gamma^{2}(1-\theta) \lambda_{r}+(\gamma-\theta) \theta k_{r}{ }^{2}\right] k_{m} \Psi^{F S}
\end{gathered}
$$


where $\quad \Psi^{F S}=\frac{\alpha-\beta\left(c_{m}+c_{r}\right)}{2 \beta(1-\gamma) \gamma \lambda_{m}\left(2 \beta \gamma \lambda_{r}-\theta k_{r}^{2}\right)-k_{m}^{2}\left[2 \beta \gamma^{2}(1-\theta) \lambda_{r}+(\gamma-\theta) \theta k_{r}^{2}\right]}$. Moreover, $w^{F S *}=$ $(1-\theta)\left[p^{F S *}-\left(c_{m}+c_{r}\right)\right]+c_{m}$ can be derived by the unit profit margin sharing structure.

\section{References}

1. Alshehhi, A.; Nobanee, H.; Khare, N. The Impact of Sustainability Practices on Corporate Financial Performance: Literature Trends and Future Research Potential. Sustainability 2018, 10, 494. [CrossRef]

2. Kim, J.; Kim, J. Corporate Sustainability Management and Its Market Benefits. Sustainability 2018, $10,1455$. [CrossRef]

3. Kuchinka, D.; Balazs, S.; Gavriletea, M.; Djokic, B.-B. Consumer Attitudes toward Sustainable Development and Risk to Brand Loyalty. Sustainability 2018, 10, 997. [CrossRef]

4. Oroian, C.; Safirescu, C.; Harun, R.; Chiciudean, G.; Arion, F.; Muresan, I.; Bordeanu, B. Consumers' Attitudes towards Organic Products and Sustainable Development: A Case Study of Romania. Sustainability 2017, 9 , 1559. [CrossRef]

5. JustMeans. Nike's Yearly CSR Budget is $\$ 25$ Million but Refuses to Pay $\$ 2.2$ Million in Severance to Honduran Garment Workers. Available online: http:/ justmeans.com/blogs/nike-spends-25-million-on-csr-annuallyrefuses-to-pay-22-million-in-severance-to-honduran (accessed on 14 April 2018).

6. Miller, D.; Merrilees, B. Linking retailer corporate brand and environmental sustainability practices. J. Prod. Brand Manag. 2013, 22, 437-443. [CrossRef]

7. Huffington Post. The Real March Madness: Nike Ditches University Commitments. Available online: https:/ / www.huffingtonpost.com/entry/the-real-march-madness-nike-ditches-university-commitments_ us_58deba30e4b0d804fbbb72b7 (accessed on 14 April 2018).

8. Human Thread Campaign. Fashion Transparency Index. Available online: http://www.humanthreadcampaign. org/wp-content/uploads/2017/06/FR_FashionTransparencyIndex2017.pdf (accessed on 14 April 2018).

9. The Guardian. Walmart Is Slapping Itself on the Back for Sustainability but it still Has a Way to Go. 2015. Available online: https:/ /www.theguardian.com/sustainable-business/2015/nov/18/walmart-climatechange-carbon-emissions-renewabe-energy-environment (accessed on 18 May 2018).

10. Govindan, K. Sustainable consumption and production in the food supply chain: A conceptual framework. Int. J. Prod. Econ. 2018, 195, 419-431. [CrossRef]

11. Grosvold, J.; Hoejmose, S.U.; Roehrich, J.K. Squaring the circle: Management, measurement and performance of sustainability in supply chains. Supply Chain Manag. 2014, 19, 292-305. [CrossRef]

12. Björklund, M.; Forslund, H.; Isaksson, M.P. Exploring logistics-related environmental sustainability in large retailers. Int. J. Retail Distrib. Manag. 2016, 44, 38-57. [CrossRef]

13. Hassini, E.; Surti, C.; Searcy, C. A literature review and a case study of sustainable supply chains with a focus on metrics. Int. J. Prod. Econ. 2012, 140, 69-82. [CrossRef]

14. Narasimhan, R.; Schoenherr, T.; Jacobs, B.W.; Kim, M.K. The financial impact of FSC certification in the United States: A contingency perspective. Decis. Sci. J. 2015, 46, 527-563. [CrossRef]

15. Kim, Y.H.; Davis, G.F. Challenges for global supply chain sustainability: Evidence from conflict minerals reports. Acad. Manag. J. 2016, 59, 1896-1916. [CrossRef]

16. Paulraj, A.; Blome, C. Plurality in environmental supply chain mechanisms: Differential effects on triple bottom line outcomes. Int. J. Oper. Prod. Manag. 2017, 37, 1010-1030. [CrossRef]

17. Mani, V.; Gunasekaran, A.; Delgado, C. Enhancing supply chain performance through supplier social sustainability: An emerging economy perspective. Int. J. Prod. Econ. 2018, 195, 259-272. [CrossRef]

18. Unruh, G.; Kiron, D.; Kruschwitz, N.; Reeves, M.; Rubel, H.; Zum Felde, A.M. Investing for a sustainable future: Investors care more about sustainability than many executives believe. MIT Sloan Manag. Rev. 2016, $57,3-28$.

19. Lal, R.; Narasimhan, C. The Inverse Relationship Between Manufacturer and Retailer Margins: A Theory. Mark. Sci. 1996, 15, 132-151. [CrossRef]

20. Lewis, L.E.; Schmidt, K.; Duvall, M.N. Retailer sustainability and the supply chain. Nat. Resour. Environ. $2012,26,18-22$. 
21. Lavorata, L. Influence of retailers' commitment to sustainable development on store image, consumer loyalty and consumer boycotts: Proposal for a model using the theor. J. Retail. Consum. Serv. 2014, 21, 1021-1027. [CrossRef]

22. He, H.; Li, Y. CSR and Service Brand: The Mediating Effect of Brand Identification and Moderating Effect of Service Quality. J. Bus. Ethics 2011, 100, 673-688. [CrossRef]

23. Roy, V.; Schoenherr, T.; Parikshit, C. The thematic landscape of literature in sustainable supply chain management (SSCM): A review of the principal facets in SSCM development. Int. J. Oper. Prod. Manag. 2018, 38, 1091-1124. [CrossRef]

24. Drumwright, M.E. Socially responsible organizational buying: Environmental concern as a noneconomic buying criterion. J. Mark. 1994, 58, 1-19. [CrossRef]

25. Carter, C.R.; Rogers, D.S. A framework of sustainable supply chain management moving toward new theory. Int. J. Retail Distrib. Manag. 2008, 38, 360-387. [CrossRef]

26. Golicic, S.L.; Smith, C.D. A Meta-Analysis of Environmentally Sustainable Supply Chain Management Practices and Firm Performance. J. Supply Chain Manag. 2013, 49, 78-95. [CrossRef]

27. Markman, G.D.; Krause, D. Theory building surrounding sustainable supply chain management: Assessing what we know, exploring where to go. J. Supply Chain Manag. 2016, 52, 3-10. [CrossRef]

28. Pagell, M.; Shevchenko, A. Why research in sustainable supply chain management should have no future. J. Supply Chain Manag. 2014, 50, 44-55. [CrossRef]

29. Touboulic, A.; Walker, H. Theories in sustainable supply chain management: A structured literature review. Int. J. Phys. Distrib. Logist. 2015, 45, 16-42. [CrossRef]

30. Montabon, F.; Pagell, M.; Wu, Z. Making Sustainability Sustainable. J. Supply Chain Manag. 2016, 52, 11-27. [CrossRef]

31. Cao, M.; Zhang, Q. Supply chain collaboration: Impact on collaborative advantage and firm performance. J. Oper. Manag. 2011, 29, 163-180. [CrossRef]

32. Fawcett, S.E.; McCarter, M.W.; Fawcett, A.M.; Webb, G.S.; Magnan, G.M. Why supply chain collaboration fails: The socio-structural view of resistance to relational strategies. Supply Chain Manag. 2015, 20, 648-663. [CrossRef]

33. Touboulic, A.; Walker, H. Love me, love me not: A nuanced view on collaboration in sustainable supply chains. J. Purch. Supply Manag. 2015, 21, 178-191. [CrossRef]

34. Crespin-Mazet, F.; Dontenwill, E. Sustainable procurement: Building legitimacy in the supply network. J. Purch. Supply Manag. 2012, 18, 207-217. [CrossRef]

35. Carter, C.R.; Easton, L.P. Sustainable supply chain management: Evolution and future directions. Int. J. Phys. Distrib. Logist. 2011, 41, 46-62. [CrossRef]

36. Wang, Z.; Huo, B.; Tian, Y.; Hua, Z. Effects of external uncertainties and power on opportunism in supply chains: Evidence from China. Int. J. Prod. Res. 2015, 53, 6294-6307. [CrossRef]

37. Cheng, J.H.; Sheu, J.B. Inter-organizational relationships and strategy quality in green supply chains-Moderated by opportunistic behavior and dysfunctional conflict. Ind. Mark. Manag. 2012, 41, 563-572. [CrossRef]

38. Herczeg, G.; Akkerman, R.; Hauschild, M.Z. Supply chain coordination in industrial symbiosis. In Proceedings of the 20th International EurOMA Conference, Dublin, Ireland, 7-12 June 2013.

39. Cachon, G.P.; Lariviere, M.A. Supply chain coordination with revenue-sharing contracts: Strengths and limitations. Manag. Sci. 2005, 51, 30-44. [CrossRef]

40. Guo, R.; Lee, H.L.; Swinney, R. Responsible sourcing in supply chains. Manag. Sci. 2015, 62, $2722-2744$. [CrossRef]

41. You, D.; Jiang, K.; Li, Z. Optimal coordination strategy of regional vertical emission abatement collaboration in a low-carbon environment. Sustainability 2018, 10, 571. [CrossRef]

42. Plambeck, E.L.; Taylor, T.A. Supplier Evasion of a Buyer's Audit: Implications for Motivating Compliance with Labor and Environmental Standards. Manuf. Serv. Oper. Manag. 2015, 18, 184-197. [CrossRef]

43. Ahmadi-Javid, A.; Hoseinpour, P. On a cooperative advertising model for a supply chain with one manufacturer and one retailer. Eur. J. Oper. Res. 2012, 219, 458-466. [CrossRef]

44. Cui, T.H.; Raju, J.S.; Zhang, Z.J. Fairness and channel coordination. Manag. Sci. 2007, 53, 1303-1314.

45. Dellarocas, C. Double Marginalization in Performance-Based Advertising: Implications and Solutions. Manag. Sci. 2012, 58, 1178-1195. [CrossRef] 
46. Brandenburg, M.; Govindan, K.; Sarkis, J.; Seuring, S. Quantitative models for sustainable supply chain management: Developments and directions. Eur. J. Oper. Res. 2014, 233, 299-312. [CrossRef]

47. Xiao, T.; Qi, X. Price competition, cost and demand disruptions and coordination of a supply chain with one manufacturer and two competing retailers. Omega 2008, 36, 741-753. [CrossRef]

48. Orlitzky, M.; Schmidt, F.L.; Rynes, S.L. Corporate social and financial performance: A meta-analysis. Organ. Stud. 2003, 24, 403-441. [CrossRef]

49. Heese, H.S.; Swaminathan, J.M. Product line design with component commonality and cost-reduction effort. Manuf. Serv. Oper. Manag. 2006, 8, 206-219. [CrossRef]

50. Tang, S.Y.; Gurnani, H.; Gupta, D. Managing Disruptions in Decentralized Supply Chains with Endogenous Supply Process Reliability. Prod. Oper. Manag. 2014, 23, 1198-1211. [CrossRef]

51. Yoon, J.; Rosales, C.; Talluri, S. Inter-firm partnerships-strategic alliances in the pharmaceutical industry. Int. J. Prod. Res. 2018, 56, 862-881. [CrossRef]

52. Ghosh, D.; Shah, J. Supply chain analysis under green sensitive consumer demand and cost sharing contract. Int. J. Prod. Econ. 2015, 164, 319-329. [CrossRef]

53. Jeuland, A.P.; Shugan, S.M. Managing Channel Profits. Mark. Sci. 2008, 27, 52-69. [CrossRef]

54. Gerstner, E.; Hess, J.D. Pull promotions and channel coordination. Mark. Sci. 1995, 14, 43-60.

(c) 2018 by the authors. Licensee MDPI, Basel, Switzerland. This article is an open access article distributed under the terms and conditions of the Creative Commons Attribution (CC BY) license (http://creativecommons.org/licenses/by/4.0/). 